\title{
Validation of the CFD approach for modelling roughness effect on ship resistance
}

\author{
Soonseok Song, Yigit Kemal Demirel, Mehmet Atlar, Saishuai Dai, Sandy Day, Osman Turan
}

Department of Naval Architecture, Ocean and Marine Engineering, University of Strathclyde, 100 Montrose Street, Glasgow G4 OLZ

Recently, there have been active efforts to investigate the effect of hull roughness on ship resistance using Computational Fluid Dynamics (CFD). Although, several studies demonstrated that the roughness modelling in the CFD simulations can precisely predict the increase in frictional resistance due to the surface roughness, the experimental validations have been made only for flat plates which have zero pressure gradient. This means that the validations cannot necessarily guarantee the validity of this method for other ship resistance components besides the frictional resistance. Therefore, it is worth demonstrating the validity of the roughness modelling in CFD on the total resistance of a $3 D$ hull. In this study, CFD models of a towed flat plate and a KRISO Container Ship (KCS) model were developed. In order to simulate the roughness effect in the turbulent boundary layer, a previously determined roughness function of a sand-grain surface was employed in the wall-function of the CFD model. Then the result of the CFD simulations was compared with the experimental data. The result showed a good agreement suggesting that the CFD approach can precisely predict the roughness effect on the total resistance of the $3 D$ hull. Finally, the roughness effects on the individual ship resistance components were investigated.

\section{Introduction}

The roughness of a ship's hull arises from a variety of causes, such as corrosion, failure of marine coatings, and the colonisation of biofouling (Tezdogan and Demirel, 2014; Demirel et al., 2017a). Its penalty is a ship speed loss at constant power, or, an increased power consumption at a constant speed (Townsin, 2003). In economic and environmental perspectives, predicting the effect of hull roughness is important for better scheduling of dry-docking as well as better choices of marine coatings.

The boundary layer similarity law analysis proposed by Granville $(1958 ; 1978)$ has been widely used to predict the roughness effect on ship frictional resistance. The benefit of using this method is that once the roughness function, $\Delta U^{+}$, of the surface is known, the skin friction with the same roughness can be extrapolated for flat plates with arbitrary lengths and speeds. Accordingly, many researchers have predicted the effect of hull roughness using this method (Schultz, 2002; Schultz, 2004; Shapiro, 2004; Schultz, 2007; Flack and Schultz, 2010; Schultz et al., 2011; Demirel, 2015; Demirel et al., 2017a; Li et al., 2019; Demirel et al., 2019). Recently, Song et al. (2019a) demonstrated the validity of the use of this method for predicting the roughness effect on ship resistance, by conducting a series of towing tests of a flat plate and a model ship in smooth and rough surface conditions.

However, this scaling method has several shortcomings as criticised by Demirel et al. (2017b). Due to the assumption of a flat plate, this method neglects the three-dimensional (3D) effects. It cannot thus 
consider the roughness effect on the other ship resistance components apart from the frictional resistance. The assumption of uniform and constant roughness function along the flat plate is another arguable point of this method.

Recently, the use of Computational Fluid Dynamics (CFD) is considered as an effective alternative to improve these shortcomings (Atlar et al., 2018). The merit of using CFD is that the distribution of the local friction velocity, $u_{\tau}$, is dynamically computed for each discretised cell, and therefore the dynamically varying roughness Reynolds number, $k^{+}$, and corresponding roughness function, $\Delta U^{+}$, can be considered in the computation. The $3 \mathrm{D}$ effects can also be taken into account, and the simulations are free from the scale effects if they are modelled in full-scale.

Correspondingly, there have been an increasing number of studies utilising CFD modelling to predict the effect of surface roughness on ship resistance (Demirel et al., 2014; Demirel et al., 2017b; Farkas et al., 2018; Song et al., 2019b) and propeller performance (Owen et al., 2018; Song et al., 2019c), as well as ship self-propulsion characteristics (Song et al., 2020). These recent studies suggest that the hull roughness does not only increase the ship frictional resistance but also affects the viscous pressure resistance and the wave making resistance.

Although several studies validated their CFD approaches by comparing the simulation results with the experimental data (Demirel et al., 2014; Song et al., 2019b), the validations were merely performed against the towing tests of flat plates, which have no pressure gradients. That is to say, these validation are only valid for the frictional resistance, and thus it cannot guarantee the validity of it for other resistance components originating from the $3 \mathrm{D}$ shape of the ship hulls. Therefore, the validity of the CFD approach for $3 \mathrm{D}$ hulls still remains to be demonstrated.

To the best of the authors' knowledge, there is no specific study to validate the CFD modelling of hull roughness against ship model test. Therefore, this study aims to fill this gap by developing a CFD model to predict the effect of the hull roughness and performing a validation study by comparing with the experimental data of a model ship with a rough surface.

In this study, an Unsteady Reynolds Averaged Navier-Stokes (URANS) based towed ship model was developed to predict the effect of hull roughness on ship resistance. The roughness function of a sand grain surface, which was determined from our previous study, was employed in the wall-function of the CFD model. The CFD simulations of the model ship were conducted at a range of speeds in the smooth and rough surface conditions. The predicted total resistance coefficients were, then, compared with the experimental data of a model ship with the same surface roughness for validation purposes.

This paper is organised as follows: The methodology of the current study is explained in Section 2, including the mathematical formulations, the roughness function and the modified wall-function approach, geometry and the boundary conditions and mesh generations. Section 3 presents the spatial and temporal verification studies and validation of the current CFD approach, as well as further investigations such as the effect of hull roughness on the individual ship resistance components and the effects on the flow characteristics around the hull. 


\section{Methodology}

A schematic illustration of the current study is shown in Fig.1. In this study, CFD models were developed to simulate the towing tests conducted in our previous study (Song et al., 2019a), which involves the towing tests of a flat plate and a KCS model ship in the smooth and rough surface conditions (Fig. 2). In order to represent the surface roughness of the sand-grain surface, the roughness function model was employed in the wall-function of the CFD model. The simulations results of the flat plate and model ship in the smooth and rough surface conditions were then compared with the experimental data to demonstrate the validity of the CFD approach for predicting the effect of hull roughness on the ship resistance.

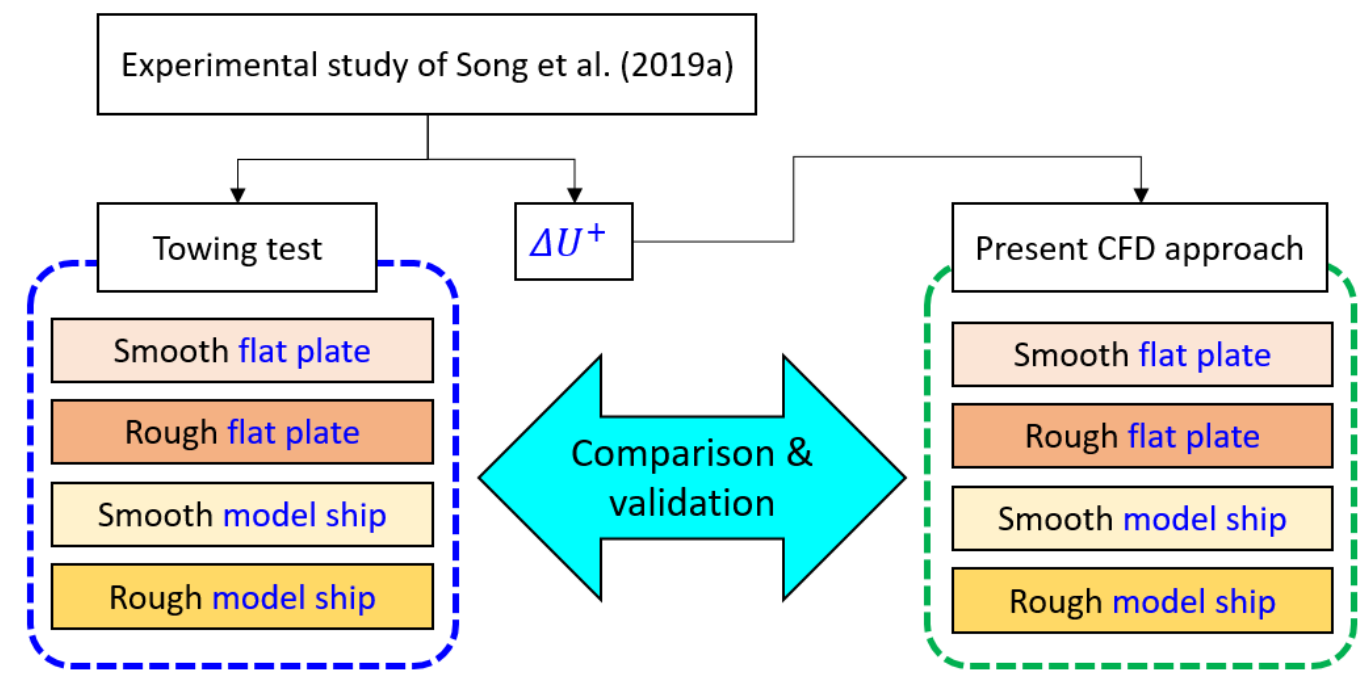

Fig. 1 Schematic illustration of the current methodology 


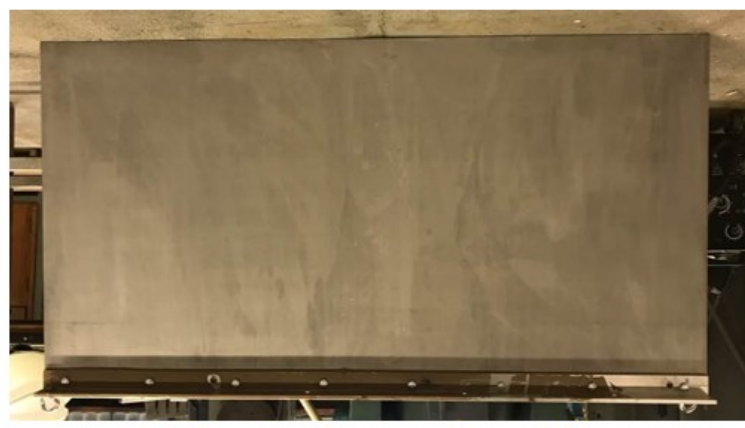

(a) Flat plate in smooth condition

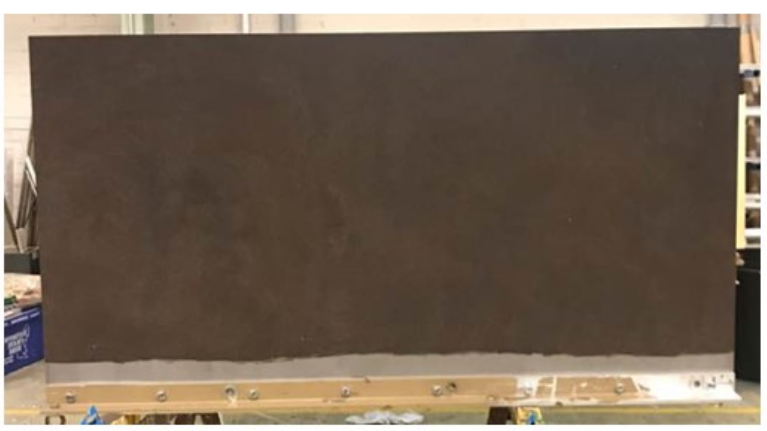

(b) Flat plate in rough condition

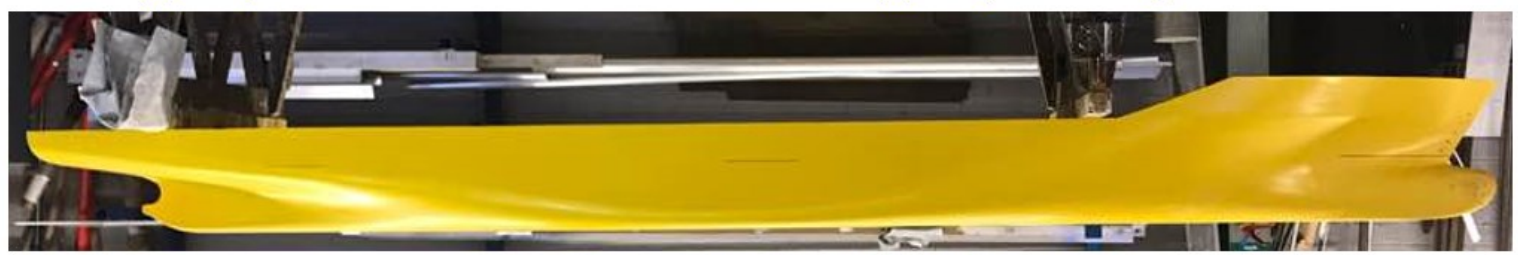

(c) KCS model in smooth condition

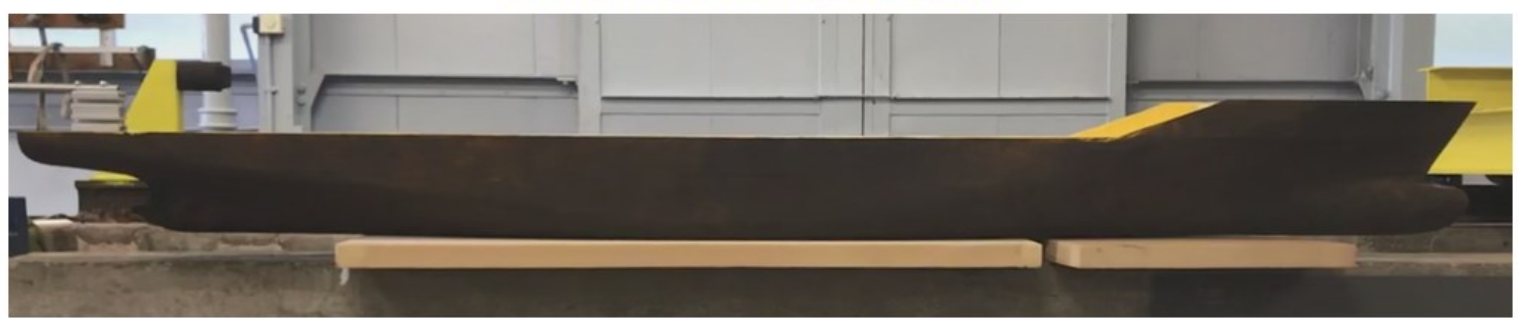

(d) KCS model in rough condition

Fig. 2 Flat plate and model ship used by Song et al. (2019a)

\subsection{Numerical modelling}

\subsubsection{Mathematical formulations}

The CFD models were developed based on the unsteady Reynolds-averaged Navier-Stokes (URANS) method using a commercial CFD software package, STAR-CCM+ (version 12.06).

The averaged continuity and momentum equations for incompressible flows may be given in tensor notation and Cartesian coordinates as in the following two equations (Ferziger and Peric, 2002).

$$
\begin{gathered}
\frac{\partial\left(\rho \bar{u}_{i}\right)}{\partial x_{i}}=0 \\
\frac{\partial\left(\rho \bar{u}_{i}\right)}{\partial t}+\frac{\partial}{\partial x_{j}}\left(\rho \bar{u}_{i} \bar{u}_{j}+\rho \overline{u_{\imath}^{\prime} u_{\jmath}^{\prime}}\right)=-\frac{\partial \bar{p}}{\partial x_{i}}+\frac{\partial \bar{\tau}_{i j}}{\partial x_{j}}
\end{gathered}
$$

where, $\rho$ is the density, $\bar{u}_{i}$ is the averaged velocity vector, $\rho \overline{u_{\imath}^{\prime} u_{\jmath}^{\prime}}$ is the Reynolds stress, $\bar{p}$ is the averaged pressure, $\bar{\tau}_{i j}$ is the mean viscous stress tensor components. This viscous stress for a Newtonian fluid can be expressed as 


$$
\bar{\tau}_{i j}=\mu\left(\frac{\partial \bar{u}_{i}}{\partial x_{j}}+\frac{\partial \bar{u}_{j}}{\partial x_{i}}\right)
$$

where, $\mu$ is the dynamic viscosity. Using the Boussinesq hypothesis, the Reynolds stress can be written as

$$
-\rho \overline{u_{\imath}^{\prime} u_{\jmath}^{\prime}}=\mu_{t}\left(\frac{\partial \bar{u}_{i}}{\partial x_{j}}+\frac{\partial \bar{u}_{j}}{\partial x_{i}}\right)-\frac{2}{3}\left(\rho k+\mu_{t} \frac{\partial \bar{u}_{k}}{\partial x_{k}}\right) \delta_{i j}
$$

where, $\mu_{t}$ is the turbulent eddy viscosity, $k$ is turbulent kinetic energy, and $\delta_{i j}$ is the Kronecker delta.

In the CFD solver, the computational domains were discretised and solved using a finite volume method. The second-order upwind convection scheme and a first-order temporal discretisation were used for the momentum equations. The overall solution procedure was based on a Semi-Implicit Method for PressureLinked Equations (SIMPLE) type algorithm. 10 inner iterations

The shear stress transport (SST) $k$ - $\omega$ turbulence model (Menter, 1994) was used to predict the effects of turbulence, which combines the advantages of the $k-\omega$ and the $k-\varepsilon$ turbulence model. This model uses a $k-\omega$ formulation in the inner parts of the boundary layer and a $k-\varepsilon$ formulation in the free-stream for a more accurate near wall treatment with less sensitivity of inlet turbulence properties, which leads to a better prediction in adverse pressure gradients and separating flow. A second-order convection scheme was used for the equations of the turbulent model.

For the free surfaces, the Volume of Fluid (VOF) method was used with High Resolution Interface Capturing (HRIC).

\subsubsection{Roughness function}

The roughness leads to an increase in turbulence, and hence the turbulent stress, wall shear stress and finally the skin friction increases. This effect can be also observed as a downward shift in the velocity profile in the log-law region. This downward shift is termed as the 'roughness function', $\Delta U^{+}$. The nondimensional velocity profile in the log-law region for a rough surface is then given as

$$
U^{+}=\frac{1}{\kappa} \ln y^{+}+B-\Delta U^{+}
$$

The roughness function, $\Delta U^{+}$is a function of the roughness Reynolds number, $k^{+}=k U_{\tau} / v$. It is of note that $\Delta U^{+}$simply vanishes in the case of a smooth condition. Song et al. (2019a) determined the roughness functions of the sand-grain surface (60/80 grit aluminium oxide abrasive powder), using the result of the towing tests of the flat plate in the smooth and rough surface conditions. They presented the roughness functions, $\Delta U^{+}$, against the roughness Reynolds number, $k^{+}$, based on different choices of the representative roughness heights, $k$. In this study, the roughness function obtained based on the use of the maximum peak to trough roughness height over a $50 \mathrm{~mm}$ interval, $R t_{50}$, was used in the CFD model $\left(k=R t_{50}=353 \mu \mathrm{m}\right)$. One may notice that this is a very rough case.

In order to employ the roughness function in the wall-function of the CFD model, a roughness function model was proposed as, 


$$
\Delta U^{+}=\left\{\begin{array}{ccc}
0 & \rightarrow & k^{+}<3 \\
\frac{1}{\kappa} \ln \left(0.49 k^{+}-3\right)^{\sin \left[\frac{\pi}{2} \frac{\log \left(k^{+} / 3\right)}{\log (25 / 3)}\right]} & \rightarrow & 3 \leq k^{+}<25 \\
\frac{1}{\kappa} \ln \left(0.49 k^{+}-3\right) & \rightarrow & 25 \leq k^{+}
\end{array}\right.
$$

in which, $\kappa$ is the von-Karman constant $(\kappa=0.42)$. As shown in Fig. 3, an excellent agreement was achieved between the proposed roughness function model and the experimental roughness function of Song et al. (2019a).

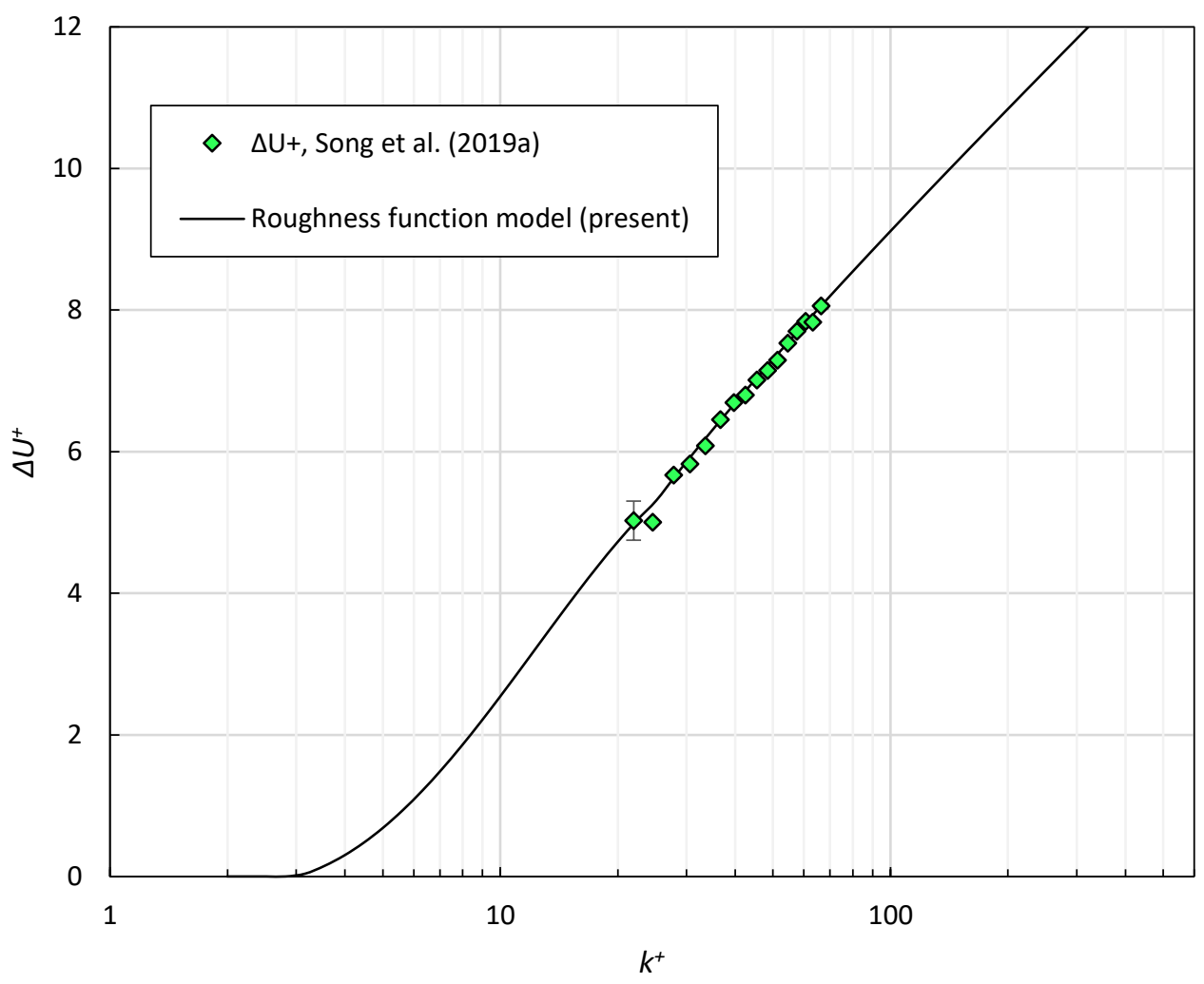

Fig. 3 Experimental roughness function of Song et al. (2019a) and the proposed roughness function model

\subsection{Geometry and boundary conditions}

\subsubsection{Flat plate simulation}

Fig. 4 shows the dimensions and the boundary conditions used for the flat plate simulations. The size of the computational domain was selected to represent the towing test of Song et al. (2019a). For the two opposite faces at the $x$-direction, a velocity inlet boundary condition was applied for the inlet freestream boundary condition, and a pressure outlet was chosen for the outlet boundary condition. The 
bottom and the side walls of the tank were selected as slip-walls and to represent the towing tank in the Kelvin Hydrodynamics Laboratory, where the towing tests were conducted. In order to save the computational time, a symmetry boundary condition was applied on the vertical centre plane $(y=0)$, so that only a half of the plate and the control volume were taken into account.
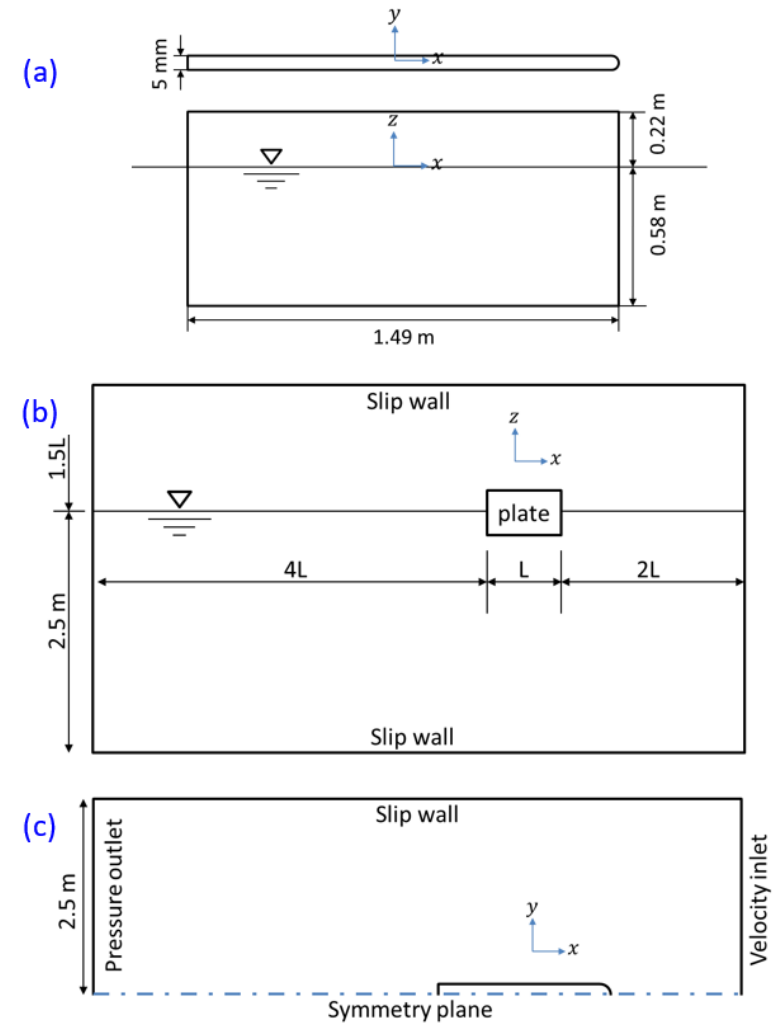

Fig. 4 The dimensions and boundary conditions for the flat plate simulation model, (a) the flat plate, (b) profile view, (c) top view

\subsubsection{KCS model ship simulation}

Table 1 shows the principal particulars of the KCS. In this study, the CFD simulation was modelled using the scale factor of 75, as used for the towing test by Song et al. (2019a). Fig. 5 depicts an overview of the body plan, side profiles of the KCS, as well as the boundary conditions and the dimensions of the computational domain. The velocity inlet and pressure outlet boundary conditions were applied as the inlet and outlet boundary conditions. For the representation of deep water and infinite air conditions, the boundary conditions of the side walls, bottom and top of the domain were set to the velocity inlet. The vertical centre plane was defined as the symmetry plane. It is of note that the model ship was free to sink and trim in the simulations, similarly to Song et al. (2019a).

Table 1 Principal particulars of the KCS in full-scale and model-scale, adapted from Kim et al. (2001) and Larsson et al. (2013)

\begin{tabular}{lccc}
\hline Parameters & & Full-scale & Model-scale \\
\hline Scale factor & $\lambda$ & 1 & 75
\end{tabular}




\begin{tabular}{llll} 
Length between the perpendiculars & $L_{P P}(\mathrm{~m})$ & 230 & 3.0667 \\
Length of waterline & $L_{W L}(\mathrm{~m})$ & 232.5 & 3.1 \\
Beam at waterline & $B_{W L}(\mathrm{~m})$ & 32.2 & 0.4293 \\
Depth & $D(\mathrm{~m})$ & 19.0 & 0.2533 \\
Design draft & $T(\mathrm{~m})$ & 10.8 & 0.144 \\
Wetted surface area w/o rudder & $S\left(\mathrm{~m}^{2}\right)$ & 9424 & 1.6753 \\
Displacement & $\nabla\left(\mathrm{m}^{3}\right)$ & 52030 & 693.733 \\
Block coefficient & $C_{B}$ & 0.6505 & 0.6505 \\
Design speed & $V(\mathrm{knot}, \mathrm{m} / \mathrm{s})$ & 24 & 1.426 \\
Froude number & $F_{n}$ & 0.26 & 0.6505 \\
Centre of gravity & $K G(\mathrm{~m})$ & 7.28 & 0.0971 \\
Metacentric height & $G M(\mathrm{~m})$ & 0.6 & 0.008 \\
\hline
\end{tabular}

(a)
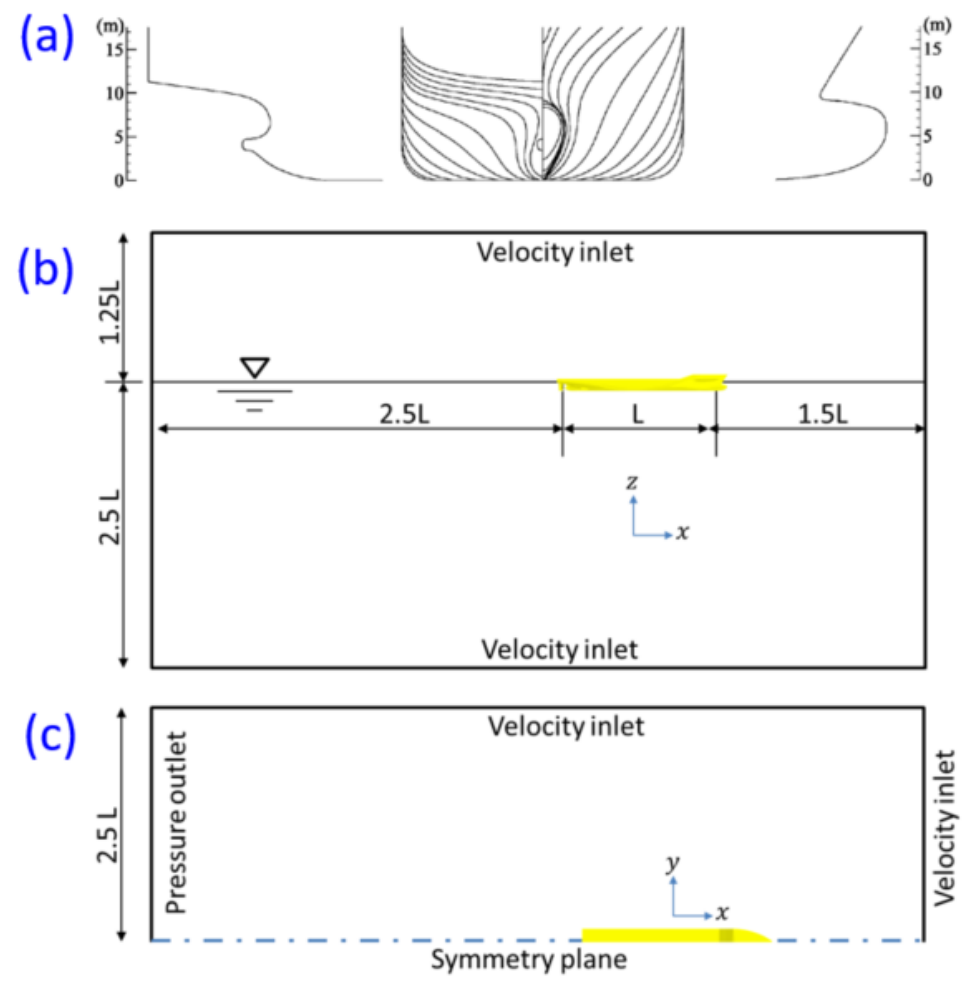

Fig. 5 Computational domain and boundary conditions of the KCS model ship simulation, (a) body plane and side profiles of the KCS, adapted from Kim et al. (2001), (b) profile view, (c) top view

\subsection{Mesh generation}

Mesh generation was performed using the built-in automated meshing tool of STAR-CCM+. Trimmed hexahedral meshes were used. Local refinements were made for finer grids in the critical regions, such as the regions near the free surface, leading and trailing edges of the flat plate and the bulbous bow of the KCS hull. The prism layer meshes were generated for near-wall refinement. The first layer cell thicknesses on the surfaces of the plate and the model ship were chosen such that the $y^{+}$values are always higher than 30, and also higher than the roughness Reynolds number values, $k^{+}$, as suggested by 
Demirel et al. (2017b). Fig. 6 and Fig. 7 show the volume meshes of the flat plate and KCS model ship simulations.

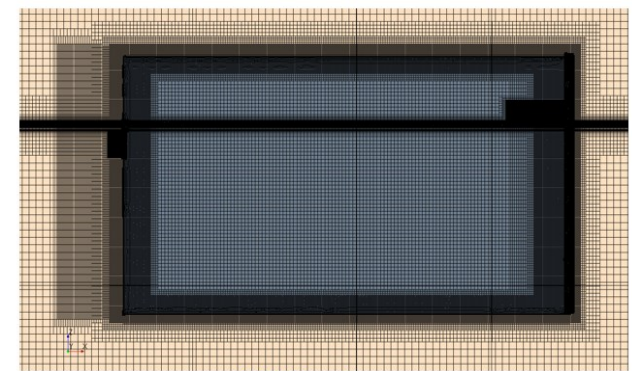

(a) Side view

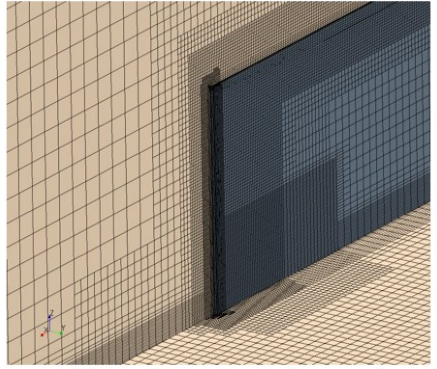

(b) Leading edge refinement

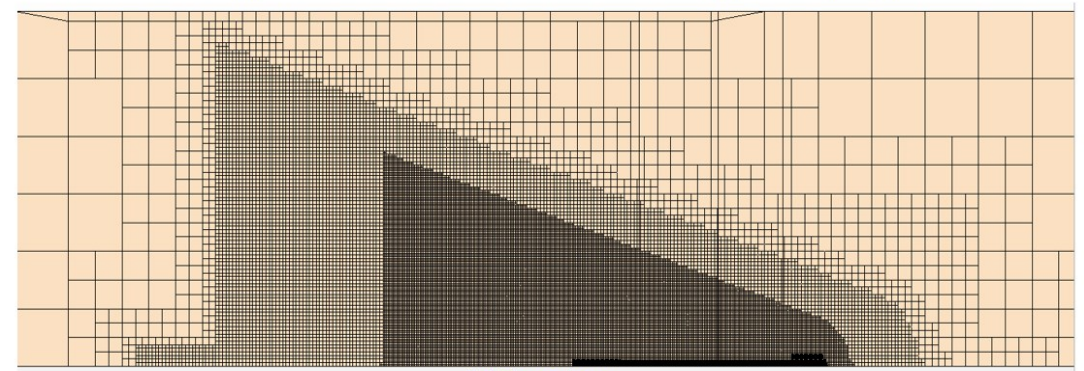

(c) Top view

Fig. 6 Volume mesh of the flat plate simulation

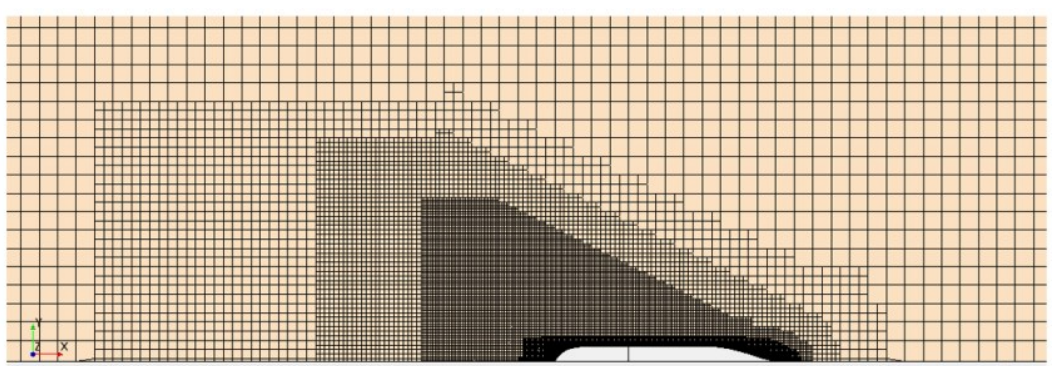

(a) Top view

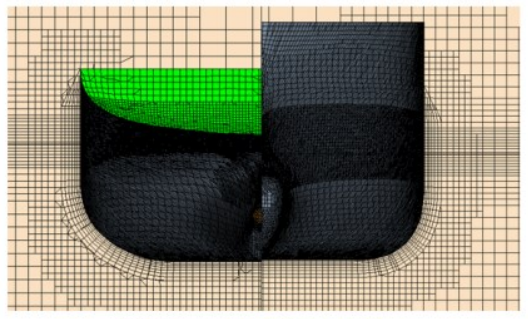

(b) Rear and front view

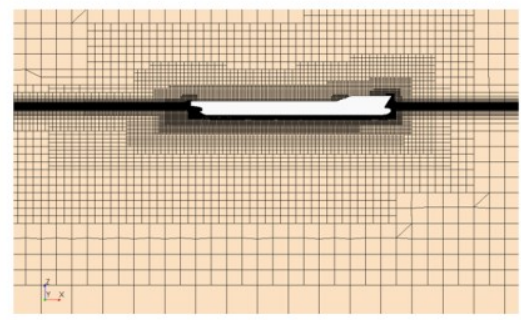

(c) Side view

Fig. 7 Volume mesh of the KCS model ship simulation 


\section{Results}

\subsection{Verification}

Convergence studies were carried out to assess the spatial and temporal uncertainties of the simulations. The Grid Convergence Index (GCI) method based on Richardson's extrapolation (1910) was used to estimate the numerical uncertainties. It is of note that, although the GCI method was first proposed for spatial convergence studies, it can also be used for a temporal convergence study, as similarly used by Tezdogan et al. (2015) and Terziev et al. (2018).

According to Celik et al. (2008) the apparent order of the method, $p_{a}$, is determined by

$$
\begin{gathered}
p_{a}=\frac{1}{\ln \left(r_{21}\right)}|\ln | \frac{\varepsilon_{32}}{\varepsilon_{21}}\left|+q\left(p_{a}\right)\right| \\
q\left(p_{a}\right)=\ln \left(\frac{r_{21}^{p_{a}}-s}{r_{32}^{p_{a}}-s}\right) \\
s=\operatorname{sign}\left(\frac{\varepsilon_{32}}{\varepsilon_{21}}\right)
\end{gathered}
$$

where, $r_{21}$ and $r_{32}$ are refinement factors given by $r_{21}=\sqrt[3]{N_{1} / N_{2}}$ for a spatial convergence study of a 3D model, or $r_{21}=\Delta t_{1} / \Delta t_{2}$ for a temporal convergence study. $N$ and $\Delta t$ are the cell number and time step, respectively. $\varepsilon_{32}=\phi_{3}-\phi_{2}, \varepsilon_{21}=\phi_{2}-\phi_{1}$, and $\phi_{k}$ denotes the key variables, i.e. $C_{T}$ and $n$ in this study.

The extrapolated value is calculated by

$$
\phi_{e x t}^{21}=\frac{r_{21}^{p} \phi_{1}-\phi_{2}}{r_{21}^{p}-1}
$$

The approximate relative error, $e_{a}^{21}$, and extrapolated relative error, $e_{e x t}^{21}$, are then obtained by

$$
\begin{aligned}
e_{a}^{21} & =\left|\frac{\phi_{1}-\phi_{2}}{\phi_{1}}\right| \\
e_{\text {ext }}^{21} & =\left|\frac{\phi_{\text {ext }}^{21}-\phi_{1}}{\phi_{\text {ext }}^{21}}\right|
\end{aligned}
$$

Finally, the fine-grid convergence index is found by

$$
G C I_{\text {fine }}^{21}=\frac{1.25 e_{a}^{21}}{r_{21}^{p}-1}
$$

\subsubsection{Spatial convergence study}

For the spatial convergence study, three different meshes were generated based on different resolutions, which are referred to as fine, medium and coarse meshes corresponding the cell numbers of $N_{1}, N_{2}$, and $N_{3}$. Table 2 depicts the required parameters for the calculation of the spatial discretisation error. The simulations were conducted in the smooth surface condition, with the inlet speeds of $4.5 \mathrm{~m} / \mathrm{s}\left(R e_{L}=\right.$ $\left.5.6 \times 10^{6}\right)$ and $1.426 \mathrm{~m} / \mathrm{s}\left(F n=0.26, R e_{L}=3.7 \times 10^{6}\right)$, for the flat plate and the KCS model simulations respectively. The total resistance coefficients, $C_{T}$, were used as the key variables. 
As indicated in the table, the numerical uncertainties of the fine meshes $\left(G C I_{\text {fine }}^{21}\right)$ for the flat plate and KCS hull simulations are $0.79 \%$ and $0.10 \%$ respectively. For accurate predictions, the fine meshes were used for further simulations in this study.

Table 2 Parameters used for the discretisation error for the spatial convergence study, key variable: $C_{T}$

\begin{tabular}{lll}
\hline & Flat plate simulation & KCS model simulation \\
\hline$N_{1}$ & 451,271 & 601,355 \\
$N_{2}$ & 913,737 & 887,428 \\
$N_{3}$ & $2,258,814$ & $1,306,433$ \\
$r_{21}$ & 1.57 & 1.21 \\
$r_{32}$ & 1.42 & 1.21 \\
$\phi_{1}$ & $3.710 \mathrm{E}-03$ & $4.471 \mathrm{E}-03$ \\
$\phi_{2}$ & $3.753 \mathrm{E}-03$ & $4.461 \mathrm{E}-03$ \\
$\phi_{3}$ & $3.836 \mathrm{E}-03$ & $4.494 \mathrm{E}-03$ \\
$\varepsilon_{32}$ & $8.34 \mathrm{E}-05$ & $3.23 \mathrm{E}-05$ \\
$\varepsilon_{21}$ & $4.30 \mathrm{E}-05$ & $-9.08 \mathrm{E}-06$ \\
$s$ & 1 & -1 \\
$e_{a}^{21}$ & $1.16 \%$ & $0.20 \%$ \\
$q$ & $3.82 \mathrm{E}-01$ & $-6.14 \mathrm{E}-03$ \\
$p_{\mathrm{a}}$ & $2.31 \mathrm{E}+00$ & $6.53 \mathrm{E}+00$ \\
$\phi_{\text {ext }}^{21}$ & $3.686 \mathrm{E}-03$ & $4.474 \mathrm{E}-03$ \\
$e_{\text {ext }}^{21}$ & $0.63 \%$ & $-0.08 \%$ \\
$G C I_{\text {fine }}^{21}$ & $0.79 \%$ & $0.10 \%$ \\
\hline
\end{tabular}

\subsubsection{Temporal convergence study}

For the temporal convergence study, three different time steps, namely $\Delta t_{1}, \Delta t_{2}$, and $\Delta t_{3}$, were used for the simulations using the fine meshes. Table 3 shows the required parameters for the calculation of the temporal discretisation error. The simulations were conducted in the smooth surface condition, with the inlet speeds of $4.5 \mathrm{~m} / \mathrm{s}\left(R e_{L}=5.6 \times 10^{6}\right)$ and $1.426 \mathrm{~m} / \mathrm{s}\left(F n=0.26, R e_{L}=3.7 \times 10^{6}\right)$, for the flat plate and KCS model simulations respectively. The total resistance coefficients, $C_{T}$, were used as the key variables.

As indicated in the table, the numerical uncertainties $\left(G C I_{\Delta t_{1}}^{21}\right)$ of the flat plate and the KCS hull simulations are $0.57 \%$ and $0.27 \%$ respectively when the smallest time steps are used $\left(\Delta t_{1}\right)$. For accurate predictions, the smallest time steps $\left(\Delta t_{1}\right)$ were used for further simulations in this study. For all the simulations, 10 inner iterations were used at each time step.

Table 3 Parameters used for the discretisation error for the temporal convergence study, key variable: $C_{T}$

\begin{tabular}{lll}
\hline & Flat plate simulation & KCS model simulation \\
\hline$\Delta t_{1}$ & $0.02 \mathrm{~s}$ & $0.01 \mathrm{~s}$ \\
$\Delta t_{2}$ & $0.04 \mathrm{~s}$ & $0.02 \mathrm{~s}$ \\
\hline
\end{tabular}




\begin{tabular}{lll}
\hline$\Delta t_{3}$ & $0.08 \mathrm{~s}$ & $0.04 \mathrm{~s}$ \\
$r_{21}, r_{32}$ & 2 & 2 \\
$\phi_{1}$ & $3.710 \mathrm{E}-03$ & $4.471 \mathrm{E}-03$ \\
$\phi_{2}$ & $3.709 \mathrm{E}-03$ & $4.528 \mathrm{E}-03$ \\
$\phi_{3}$ & $3.708 \mathrm{E}-03$ & $4.539 \mathrm{E}-03$ \\
$\varepsilon_{32}$ & $-7.00 \mathrm{E}-07$ & $1.09 \mathrm{E}-05$ \\
$\varepsilon_{21}$ & $-7.30 \mathrm{E}-07$ & $5.78 \mathrm{E}-05$ \\
$e_{a}^{21}$ & $0.02 \%$ & $1.29 \%$ \\
$p_{\mathrm{a}}$ & $6.05 \mathrm{E}-02$ & $2.41 \mathrm{E}+00$ \\
$\phi_{e x t}^{21}$ & $3.727 \mathrm{E}-03$ & $4.457 \mathrm{E}-03$ \\
$e_{e x t}^{21}$ & $-0.46 \%$ & $0.30 \%$ \\
$G C I_{\Delta t_{1}}^{21}$ & $0.57 \%$ & $0.37 \%$ \\
\hline
\end{tabular}

\subsection{Validation}

\subsubsection{Flat plate simulation}

Fig. 8 compares the total resistance coefficient, $C_{T}$, values in the smooth and rough surface conditions predicted from the current CFD simulations and the experimental data of Song et al. (2019a). The CFD simulations were conducted at the speed range of $1.5-4.5 \mathrm{~m} / \mathrm{s}$ with $1.0 \mathrm{~m} / \mathrm{s}$ interval, with the corresponding Reynolds numbers of $R e_{L}=1.9-5.6 \times 10^{6}$.

As shown in the figure, the $C_{T}$ values of the smooth flat plate predicted from the CFD simulations show an excellent agreement with the experimental data. Similarly, a good agreement was achieved between the CFD and EFD results for the $C_{T}$ of the rough flat plate apart from the under-prediction of the $C_{T}$ value at the lowest speed $\left(1.5 \mathrm{~m} / \mathrm{s}, R e_{L}=1.9 \times 10^{6}\right)$. Considering the uncertainty of the experimental $C_{T}$ values and the roughness function (Fig. 3) as well as the numerical uncertainty of the simulation, this slight under-prediction is believed to be acceptable.

This agreement suggests the validity of the use of the current CFD approach (modified wall-function approach) to predict the increased skin friction due to the surface roughness, as similarly shown by Demirel et al. (2017b) and Song et al. (2017b). 


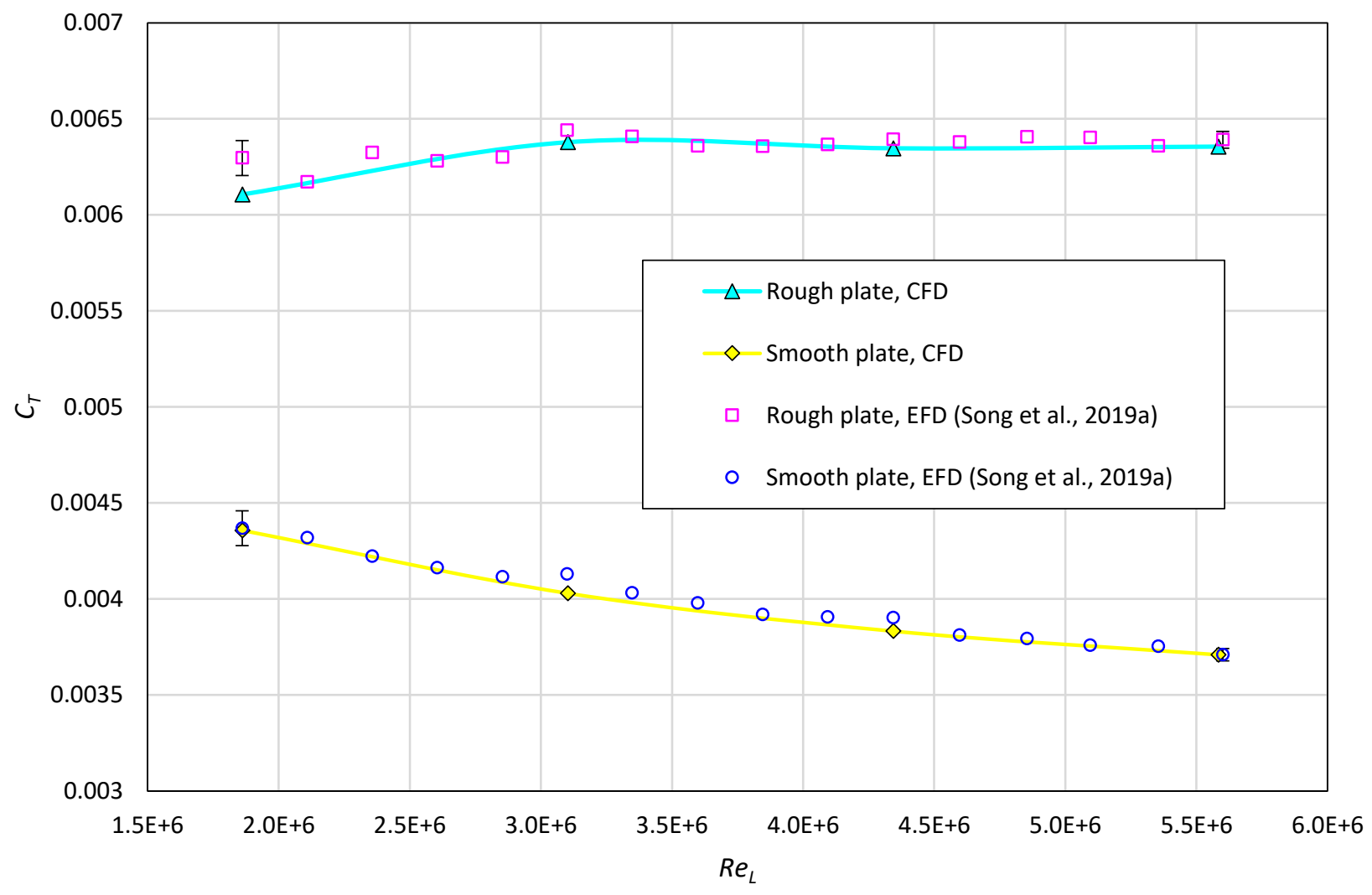

Fig. 8 Total resistance coefficient, $C_{T}$, of the towed flat plate in the smooth and rough surface conditions, predicted from the current CFD simulations and the experimental data of Song et al. (2019a)

\subsubsection{KCS model ship simulation}

Although the use of the modified wall-function approach is validated against the flat plate towing tests, this does not necessarily guarantee the validity of using this method to predict the roughness effect on the ship resistance of a 3D hull. Therefore, this section presents the comparison between the CFD approach and the experimental result of the towing test of the KCS model ship in the smooth and rough surface conditions (Song et al., 2019a).

Fig. 9 shows a comparison of the $C_{T}$ values of the KCS model ship predicted from the current CFD simulations and the experimental results (Song et al., 2019a). The CFD simulations were conducted at the speed range of $1.07-1.54 \mathrm{~m} / \mathrm{s}$, which correspond to the full-scale speed range $18-26$ knots with 2 knots interval. The corresponding Reynolds numbers are $R e_{L}=2.8-4.1 \times 10^{6}$, while the Froude numbers are $F n=0.195-0.282$. In both the smooth and rough surface conditions, the $C_{T}$ values predicted from the CFD simulations agrees well with the experimental $C_{T}$ values. Therefore, it suggests that the modified wall-function approach can accurately predict the effect of hull roughness on the total ship resistance, which includes the 3D effects.

It is of note that this is the first validation of the CFD modelling of hull roughness against ship model test. 


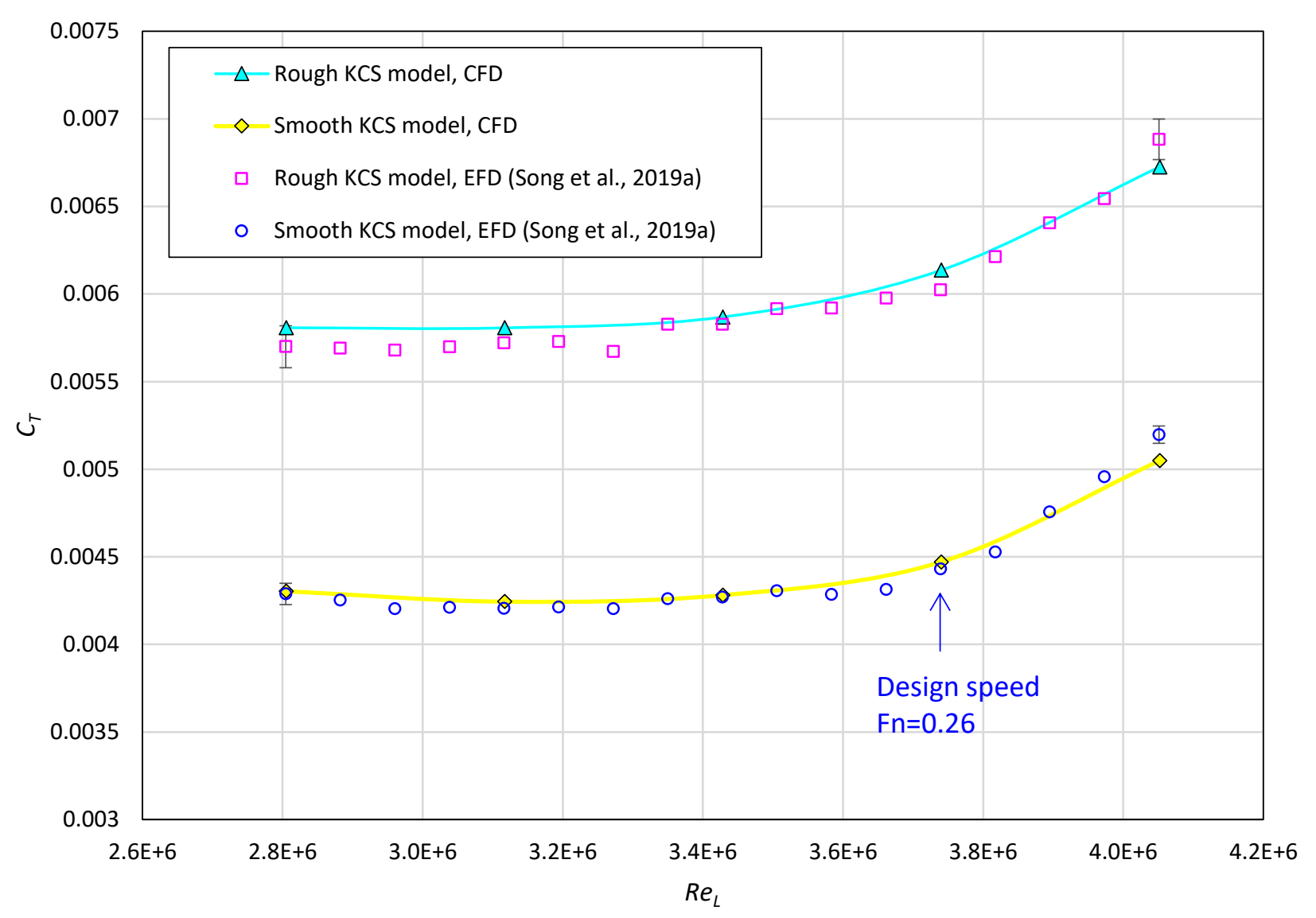

Fig. 9 Total resistance coefficient, $C_{T}$, of the KCS model ship in the smooth and rough surface conditions, predicted from the current CFD simulations and the experimental data (Song et al., 2019a)

\subsection{Effect of hull roughness on the ship resistance components}

In the previous section, the validity of the modified wall-function approach was demonstrated for predicting the effect of hull roughness on the ship total resistance. Therefore, it is worth to utilise the benefits of using CFD for better understanding the roughness effect on the individual ship resistance components. Decompositions of the ship total resistance into the different resistance components are presented in this section.

Before investigating the effect of hull roughness on the resistance components, it would be timely to restate these components in detail. The resistance coefficients can be obtained by dividing the drag, $R$, with the dynamic pressure, $\frac{1}{2} \rho V^{2}$, and the wetted surface area of the ship hull, $S$, as

$$
C=\frac{R}{\frac{1}{2} \rho S V^{2}}
$$

The total ship resistance coefficient, $C_{T}$, can be decomposed into the two main components; the frictional resistance coefficient, $C_{F}$, and the residuary resistance coefficient, $C_{R}$, given by 


$$
C_{T}=C_{F}+C_{R}
$$

The residuary resistance is can be further divided into the viscous pressure resistance coefficient, $C_{V P}$, and the wave making resistance coefficient, $C_{W}$, given by

$$
\begin{gathered}
C_{R}=C_{V P}+C_{W} \\
C_{T}=C_{F}+C_{V P}+C_{W}
\end{gathered}
$$

The viscous pressure or also known as form drag is broadly assumed to be proportional to the frictional resistance (Lewis, 1988), with the use of form factor, $k$, as given

$$
\begin{gathered}
C_{V P}=k C_{F} \\
C_{T}=(1+k) C_{F}+C_{W}
\end{gathered}
$$

The sum of frictional resistance and the viscous pressure resistance is also referred to as viscous resistance, $C_{V}$, as

$$
C_{V}=C_{F}+C_{V P}=(1+k) C_{F}
$$

\subsubsection{Frictional resistance and residuary resistance}

The total resistance coefficients, $C_{T}$, were divided into the frictional resistance coefficient, $C_{F}$, and the residuary resistance coefficient, $C_{R}$, by simply decomposing the total drag acting on the ship into the shear and pressure force components.

The $C_{F}$ and $C_{R}$ values of the KCS model in the smooth and the rough conditions are shown in Fig. 10. The $C_{F}$ values for the rough KCS model remain rather consistent with the Reynolds numbers, while the smooth $C_{F}$ values show a decreasing trend. This can be explained by the fact that $C_{F}$ tends to lose its dependency to the Reynolds number when it approaches the fully rough regime (Nikuradse, 1933), as similarly observed by other studies (e.g. Demirel et al., 2017b; Song et al. 2019a; Song et al., 2019b).

On the other hand, the rough case shows larger $C_{R}$ values than the smooth case, but the differences become smaller as the Reynolds number increases (which can be more clearly seen in Fig. 11). To fine the rationale behind this observation, further investigation was carried out by decomposing the $C_{R}$ into the $C_{V P}$ and $C_{W}$. 


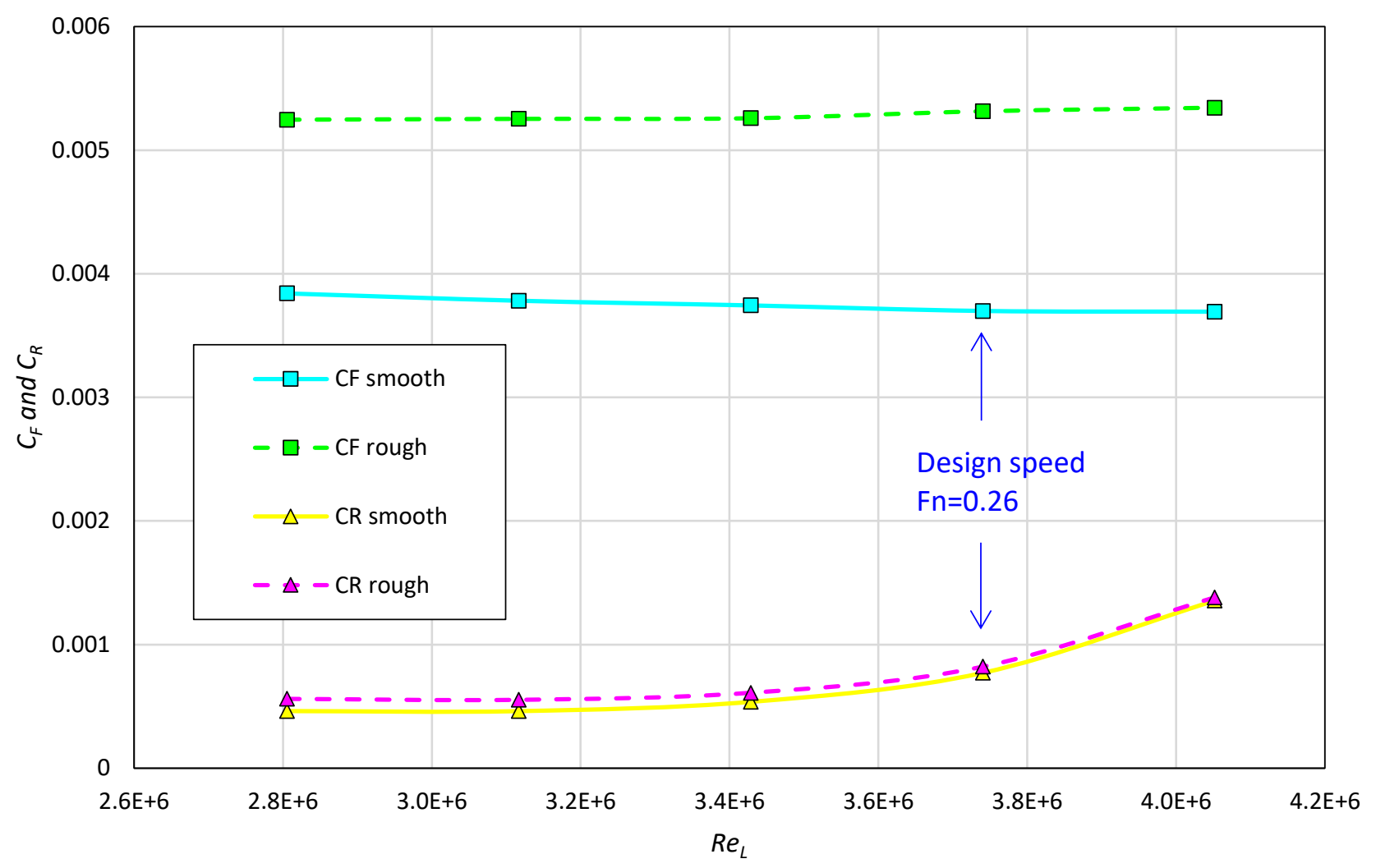

Fig. $10 C_{F}$ and $C_{R}$ values of the KCS model in the smooth and rough surface conditions

\subsubsection{Viscous pressure and wave making resistance}

In order to decompose the $C_{R}$ into the $C_{V P}$ and $C_{W}$, a similar approach was used as Song et al. (2019b). To obtain the form factor values, double-body flow simulations were conducted by modifying the CFD model. In the double-body simulations, the free surface is replaced by a symmetry plane such that no wave can be generated and hence only the viscous resistance $\left(C_{V}=C_{F}+C_{V P}\right)$ exists (Raven et al., 2008; Van et al., 2011). Then the form factor values, $k$, were calculated as

$$
k=\frac{C_{V, d b}}{C_{F, d b}}-1
$$

where $C_{V, d b}$ and $C_{F, d b}$ denote the viscous resistance and frictional resistance obtained from the doublebody flow simulations. Table 4 shows the form factor values for the smooth and rough KCS models for the given speeds. As similarly observed by Song et al. (2019b) the form factor values showed decreases due to the hull roughness.

Table $4 C_{V}, C_{V P}$ and $k$ values obtained from the double-body simulations

\begin{tabular}{lccccccc} 
& \multicolumn{2}{l}{ Smooth } & \multicolumn{5}{l}{ Rough } \\
\cline { 2 - 4 } \cline { 6 - 8 } Speed $(\mathrm{m} / \mathrm{s})$ & $C_{V, d b}$ & $C_{F, d b}$ & $k$ & & $C_{V, d b}$ & $C_{F, d b}$ & $k$ \\
\hline 1.0692 & $4.049 \mathrm{E}-03$ & $3.721 \mathrm{E}-03$ & $8.813 \mathrm{E}-02$ & & $5.539 \mathrm{E}-03$ & $5.102 \mathrm{E}-03$ & $8.578 \mathrm{E}-02$ \\
1.1880 & $3.967 \mathrm{E}-03$ & $3.646 \mathrm{E}-03$ & $8.802 \mathrm{E}-02$ & & $5.525 \mathrm{E}-03$ & $5.087 \mathrm{E}-03$ & $8.618 \mathrm{E}-02$
\end{tabular}




\begin{tabular}{lllllll}
1.3068 & $3.899 \mathrm{E}-03$ & $3.583 \mathrm{E}-03$ & $8.792 \mathrm{E}-02$ & $5.477 \mathrm{E}-03$ & $5.041 \mathrm{E}-03$ & $8.652 \mathrm{E}-02$ \\
1.4255 & $3.839 \mathrm{E}-03$ & $3.529 \mathrm{E}-03$ & $8.783 \mathrm{E}-02$ & $5.513 \mathrm{E}-03$ & $5.077 \mathrm{E}-03$ & $8.597 \mathrm{E}-02$ \\
1.5443 & $3.787 \mathrm{E}-03$ & $3.482 \mathrm{E}-03$ & $8.776 \mathrm{E}-02$ & $5.532 \mathrm{E}-03$ & $5.095 \mathrm{E}-03$ & $8.582 \mathrm{E}-02$ \\
\hline
\end{tabular}

Using the form factor values, $k, C_{V P}$ and $C_{W}$ were calculated as

$$
\begin{gathered}
C_{V P}=k C_{F} \\
C_{W}=C_{R}-C_{V P}
\end{gathered}
$$

Fig. 11 compares the $C_{R}, C_{V P}$ and $C_{W}$ values of the KCS model in the smooth and rough surface conditions. As expected, the rough KCS model has larger $C_{V P}$ values than the smooth KCS model, but the contributions of $C_{V P}$ values in $C_{R}$ show decreasing trends with increasing speeds (thus, the Reynolds number). On the other hand, the wave making resistance, $C_{W}$, values for both the smooth and rough cases increase with the speed. The discrepancy between smooth and rough $C_{W}$ is small at low speeds, but smooth $C_{W}$ becomes larger than rough $C_{W}$ as the speed increases.

Subsequently, the differences between the smooth and rough $C_{R}$ become smaller at higher Reynolds numbers as the roughness effects on the $C_{V P}$ and $C_{R}$ cancel each other. This observation of the increased $C_{V P}$ and decreased $C_{W}$ values agrees with the findings of Song et al. (2019b).

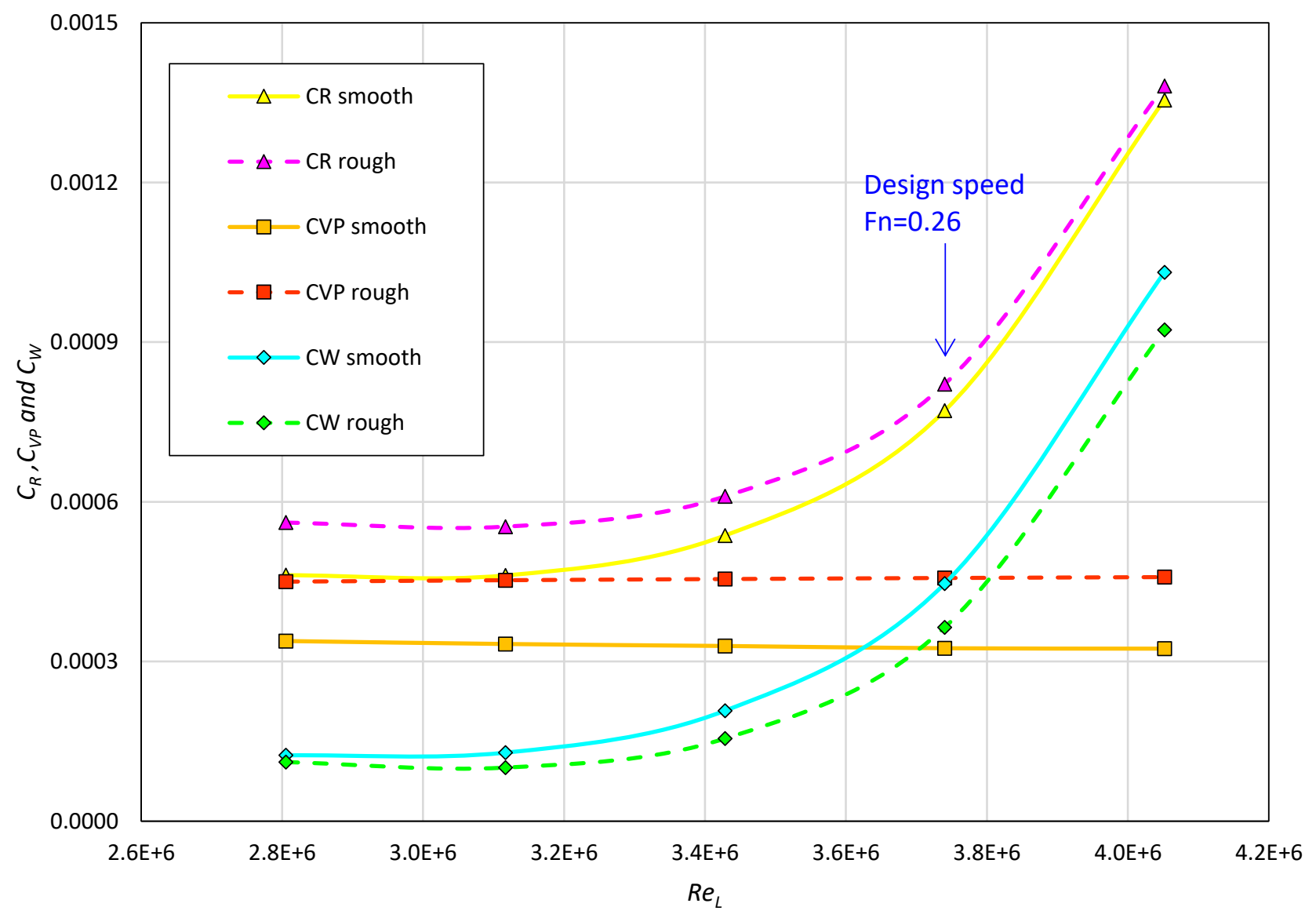

Fig. $11 C_{R}, C_{V P}$ and $C_{W}$ values of the KCS model in the smooth and rough surface conditions 


\subsection{Effect of hull roughness on the flow characteristics}

This section compares the flow characteristics around the KCS model in the smooth and rough surface conditions at its design speed $\left(V_{\text {model }}=1.43 \mathrm{~m} / \mathrm{s}, F n=0.26, R e_{L}=3.7 \times 10^{6}\right)$.

\subsubsection{Velocity field}

Fig. 12 and 13 compare the mean axial velocity contours around the stern of the KCS model ship in both the surface conditions. The mean axial velocity was normalised by dividing the velocity with the advance speed of the ship. As shown in the figures, the hull roughness resulted in the decelerated flow around the stern and it enlarged the wake field. This enlarged wake region can be closely related to the distribution of the surface pressure at the stern (16), which leads to the increase in the viscous pressure resistance.

Another notable feature is the increased boundary layer thickness due to the hull roughness as shown in Fig. 12. It can be more clearly seen in Fig. 14, where the boundary layer is represented by the slices of axial velocity contours limited to $V_{x} / V_{\text {model }}=0.9$. This increased boundary layer thickness results in increased momentum loss and hence the frictional resistance, as shown in Fig. 10. This roughness effect on the boundary layer thickness leads to increased momentum loss and thus leads to increased skin friction. This observation is in correspondence with the experimental and numerical studies of other researchers (e.g. Schultz and Flack, 2005, 2007; Demirel et al, 2017a; Song et al., 2019b).

As the enlarged wake field due to the hull roughness was observed in Fig. 13, the nominal wake fractions of the smooth and rough KCS model were calculated. Fig. 15 illustrates the distribution of the local wake fraction, $w_{n}^{\prime}=1-V_{x} / V_{\text {model }}$, at the propeller plane $\left(x=0.0175 L_{p p}\right)$. The inner and outer circles denote the hub diameter and the propeller diameter, respectively. From the figure, it is evident that the hull roughness increases the local wake fraction significantly, and it led to a $35 \%$ increase in the mean nominal wake fraction, $w_{n}(0.31$ to 0.42$)$.

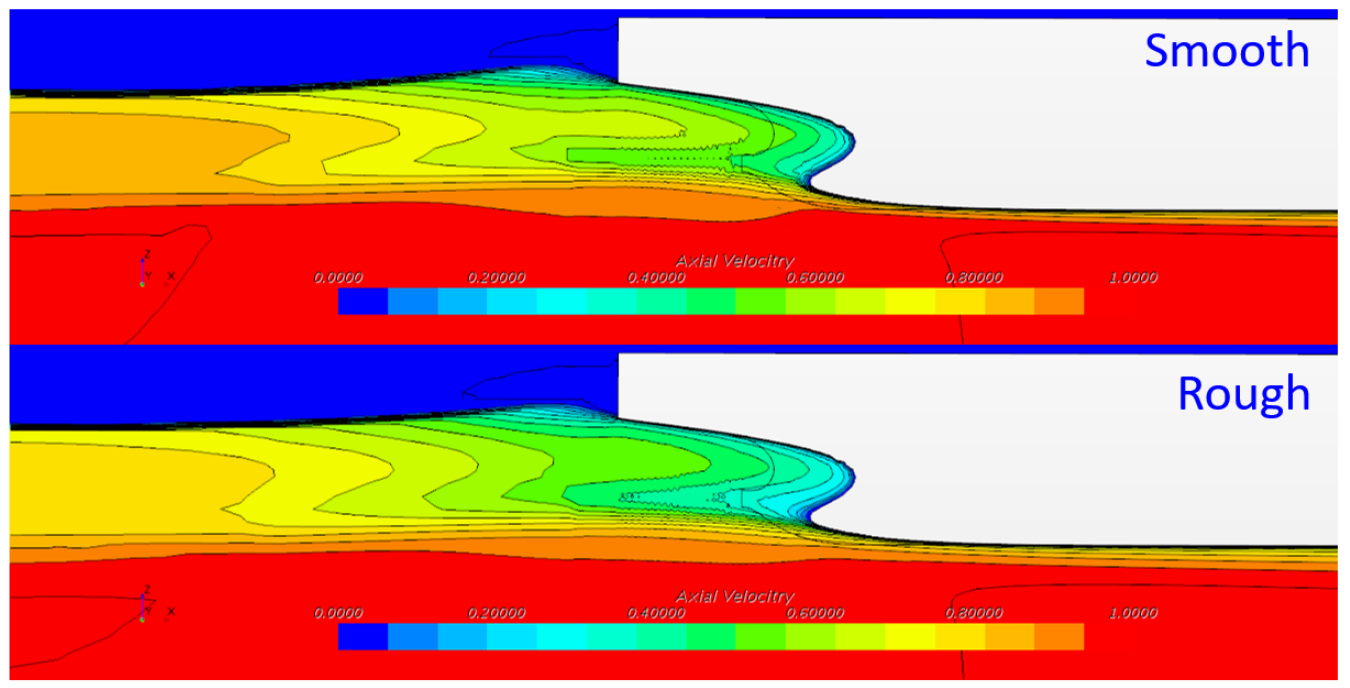

Fig. 12 Mean axial velocity contours at $y=0.006 L_{p p}$ 


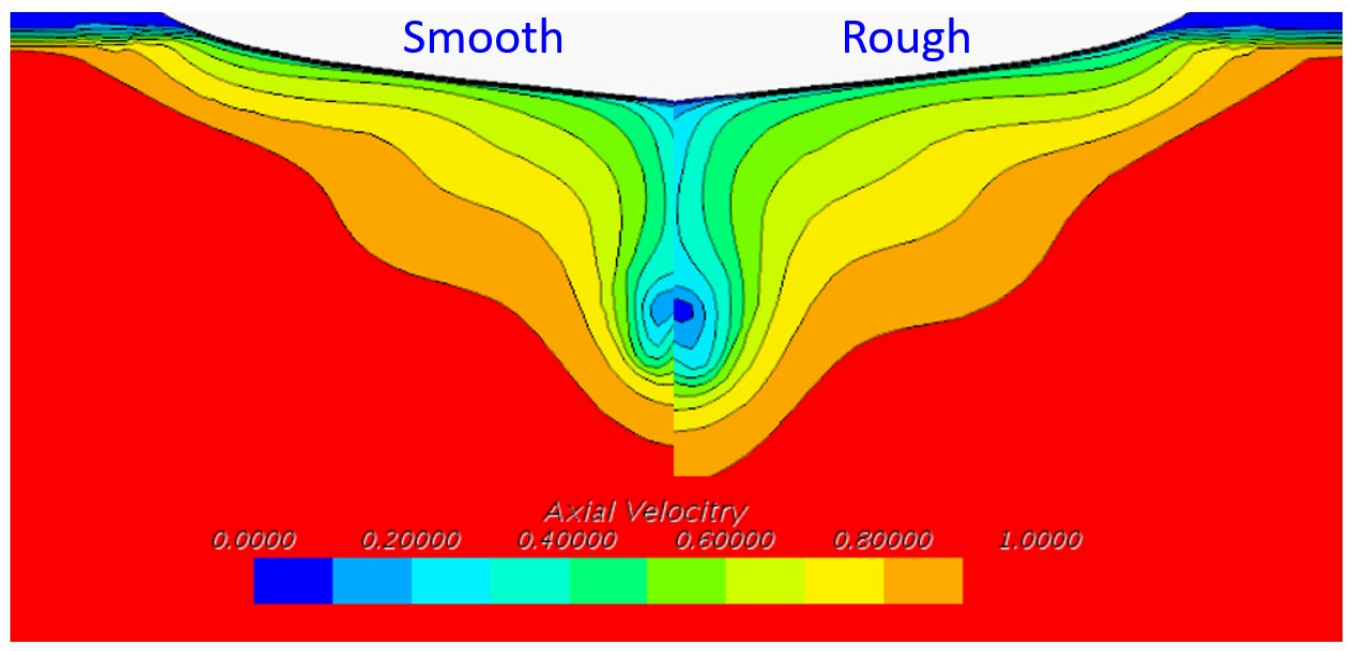

Fig. 13 Mean axial velocity contours at $x=0.0175 L_{p p}$

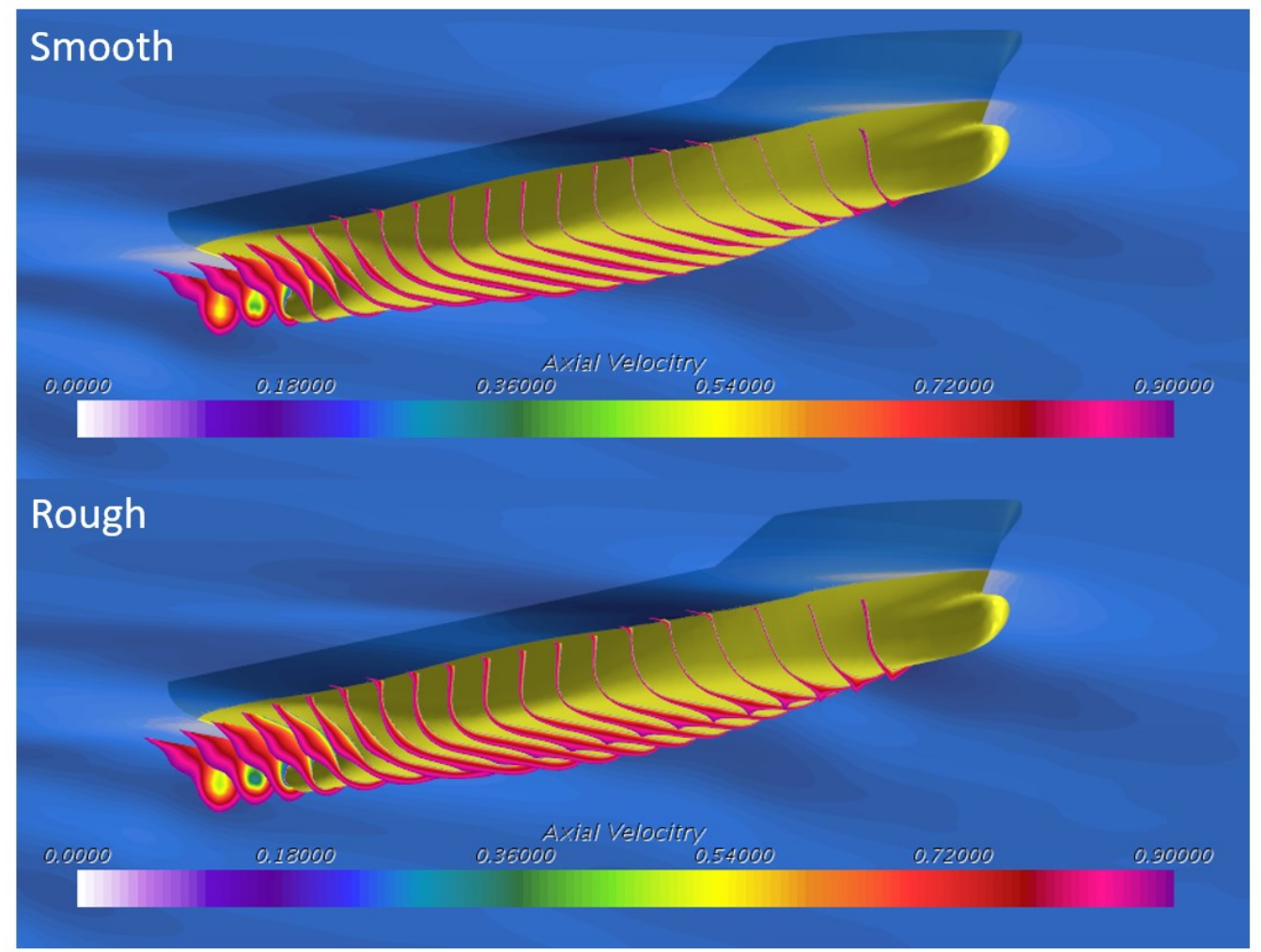

Fig. 14 Boundary layer representation by slices limited to axial velocity $\left(V_{x} / V_{\text {model }}=0.9\right)$ 

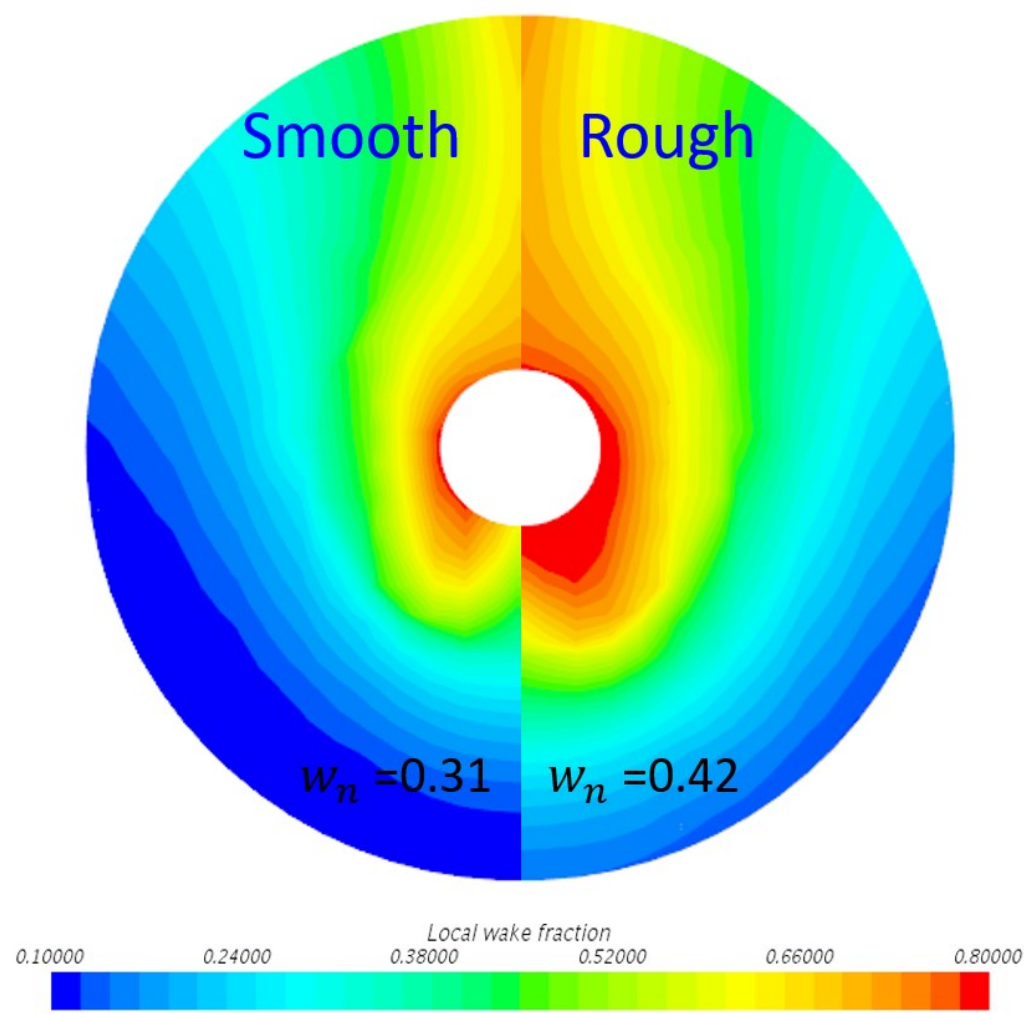

Fig. 15 Local wake fraction, $w_{n}{ }^{\prime}$, at the propeller plane

\subsubsection{Pressure field}

Fig. 16 illustrates the distribution of the dynamic pressure coefficient along the hull in the smooth and rough surface conditions. It can be seen from the figure that the rough case has smaller pressure magnitudes at the stern (i.e. reduced pressure recovery). This smaller surface pressure at the stern due to the hull roughness can be related to the increased viscous pressure resistance, $C_{V P}$, in Fig. 11.

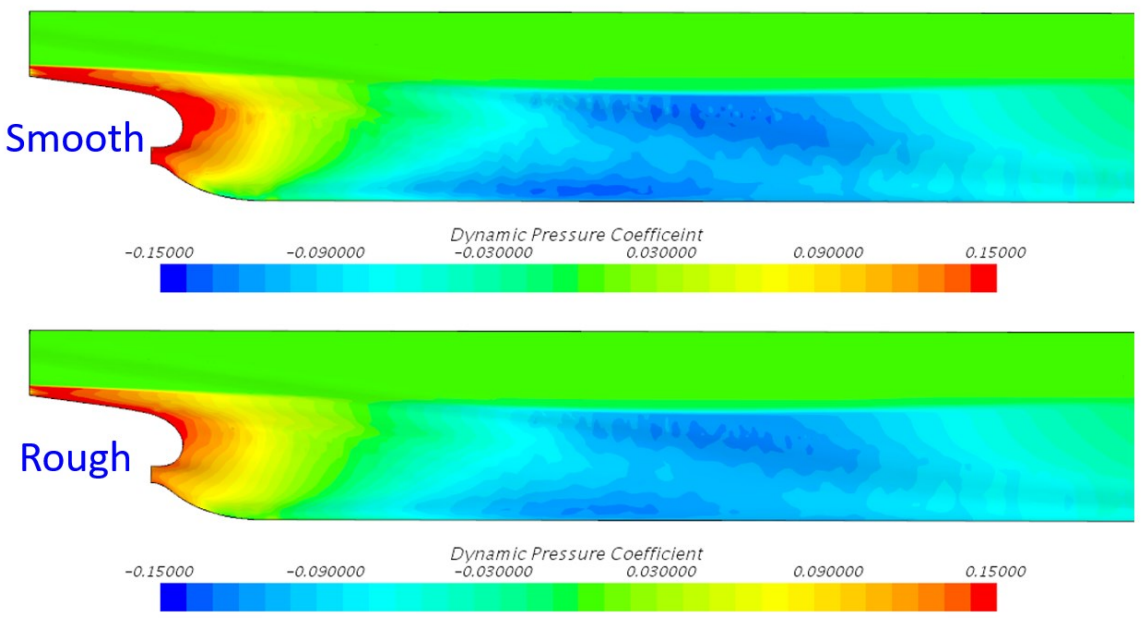

Fig. 16 Pressure distribution on the KCS model ship

\subsubsection{Wave profile}


Fig. 17 compares the wave patterns around the KCS model in the smooth and rough surface conditions. It is seen from the figure that the wave elevations around the hull are reduced by the hull roughness. This roughness effect on the wave pattern can be also seen in Fig. 18, which compares the wave elevation along the line with constant $y=0.1509 L_{p p}$. This roughness effect on the wave profile is in accordance with the reduced $C_{W}$ values due to the hull roughness as shown in Fig. 11. This observation also agrees with the findings of Demirel et al. (2017b) and Song et al. (2019b).

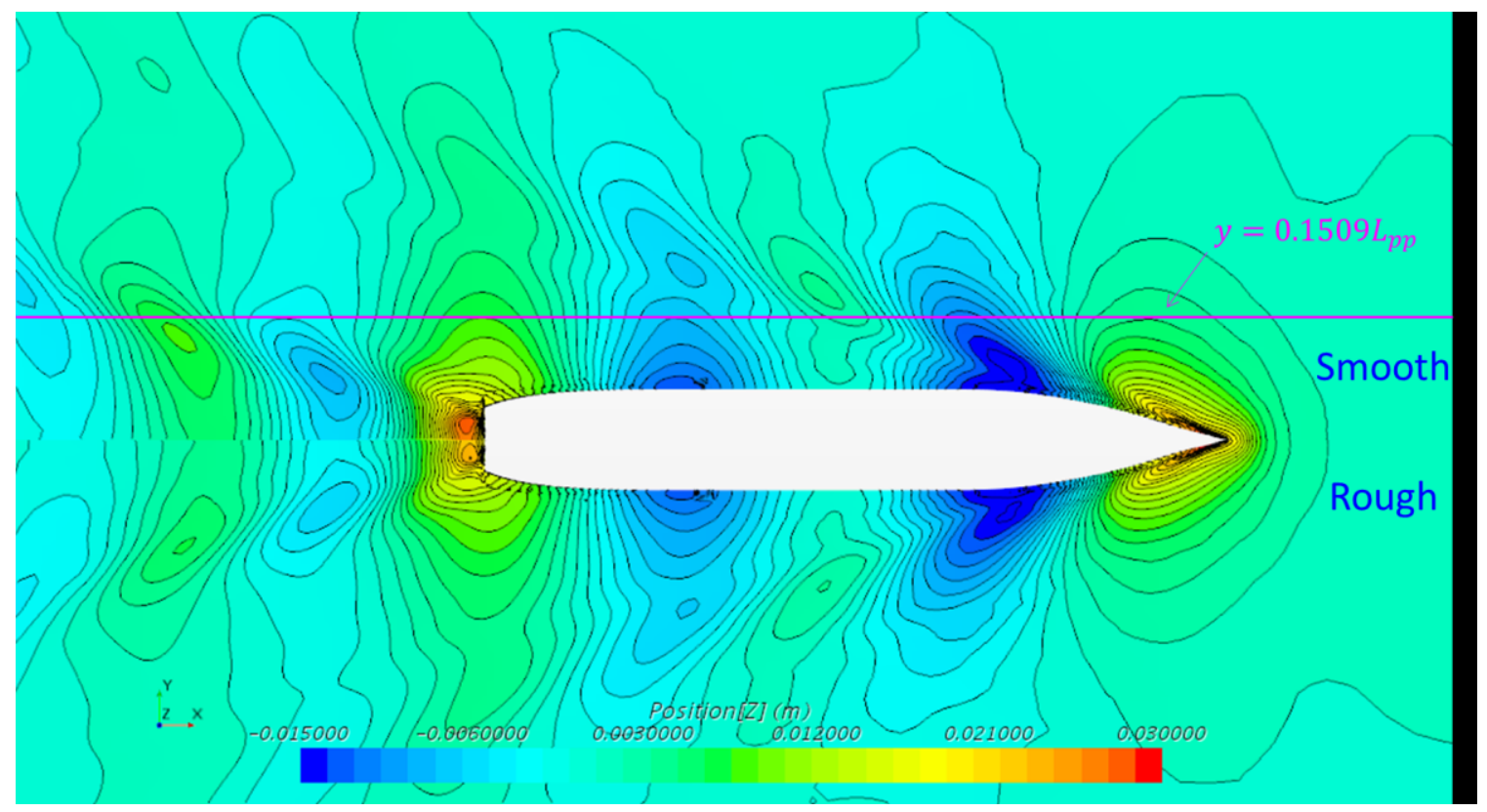

Fig. 17 Wave pattern around the KCS model

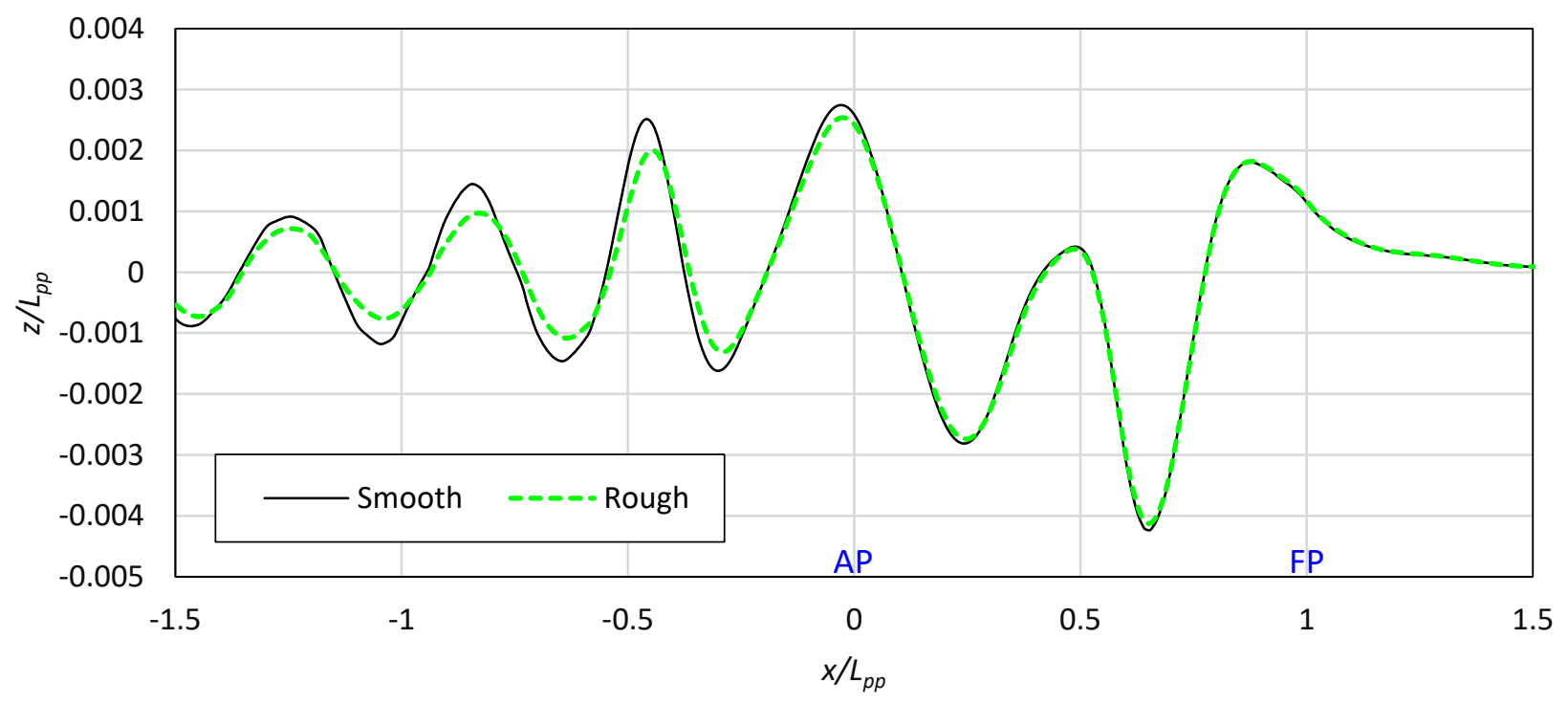

Fig. 18 Wave elevation along a line with constant $y=0.1509 L_{p p}$ 


\section{Concluding remarks}

In this study, the CFD approach to predict the effect of hull roughness on the ship resistance was validated against the experiment of a towed flat plate and a model ship in the smooth and rough surface conditions. In order to simulate the effect of the surface roughness, a roughness function model was proposed based on the roughness function of Song et al. (2019a) and employed in the wall-function of the CFD model.

Spatial and temporal convergence studies were performed using the Grid convergence Index (GCI) method, to estimate the numerical uncertainties of the proposed CFD models and to determine sufficient grid-spacings and time steps.

Fully nonlinear unsteady RANS simulations of the flat plate and the KCS model ship were conducted in the smooth and rough surface conditions. The simulation results showed excellent agreements with the experimental data of Song et al. (2019a) in both the smooth and rough surface conditions. This result suggests that the CFD approach (i.e. modified wall-function approach) can accurately predict not only the roughness effect on the skin friction, but also the total resistance of a 3D hull.

The total ship resistance predicted from the CFD simulations in the smooth and rough conditions were decomposed into individual resistance components. Significant increases in the frictional resistance, $C_{F}$, due to the hull roughness were found. Increases in the viscous pressure resistance, $C_{V P}$, and decreases in the wave making resistance, $C_{W}$, were also observed due to the hull roughness.

The effect of hull roughness on the flow characteristics around the hull was also examined. By comparing the velocity field around the KCS model in the smooth and rough conditions, a decelerated flow and enlarged wake field were observed downstream of the stern, as well as the increased boundary layer thickness. It was found that the hull roughness reduces the pressure recovery at the stern, which leads to increased viscous pressure resistance. Smaller wave elevation due to the hull roughness was also noted, which is closely related to the smaller wave making resistance for the rough case.

This study has provided the first experimental validation of the CFD approach to predict the effect of hull roughness on the ship total resistance by comparing the simulations with the model ship towing test. Apart from the effect of hull roughness, there have been several studies predicting the effect of roughness on the blades on the propeller performances using the same CFD approach. However, this approach has not been experimentally validated for propellers. Therefore, future pieces of work may include a validation study of the CFD simulations to predict the roughness effect on propellers.

\section{Acknowledgements}

It should be noted that the results were obtained using the ARCHIE-WeSt High Performance Computer (www.archie-west.ac.uk) based at the University of Strathclyde.

\section{References}

Atlar, M., Yeginbayeva, I. A., Turkmen, S., Demirel, Y. K., Carchen, A., Marino, A., \& Williams, D. (2018). A Rational Approach to Predicting the Effect of Fouling Control Systems on "In-Service" Ship Performance. GMO SHIPMAR, 24(213), 5-36. 
Celik, I. B., Ghia, U., Roache, P. J., Freitas, C. J., Coleman, H., \& Raad, P. E. (2008). Procedure for Estimation and Reporting of Uncertainty Due to Discretization in CFD Applications. Journal of Fluids Engineering, 130(7), 078001-078001-078004. doi:10.1115/1.2960953

Demirel, Y. K. (2015). Modelling the Roughness Effects of Marine Coatings and Biofouling on Ship Frictional Resistance. (PhD), University of Strathclyde, Glasgow.

Demirel, Y. K., Khorasanchi, M., Turan, O., Incecik, A., \& Schultz, M. P. (2014). A CFD model for the frictional resistance prediction of antifouling coatings. Ocean Engineering, 89, 21-31. doi:https://doi.org/10.1016/j.oceaneng.2014.07.017

Demirel, Y. K., Song, S., Turan, O., \& Incecik, A. (2019). Practical added resistance diagrams to predict fouling impact on ship performance. Ocean Engineering, 186, 106112.

doi:https://doi.org/10.1016/j.oceaneng.2019.106112

Demirel, Y. K., Turan, O., \& Incecik, A. (2017b). Predicting the effect of biofouling on ship resistance using CFD. Applied Ocean Research, 62, 100-118. doi:https://doi.org/10.1016/j.apor.2016.12.003

Demirel, Y. K., Uzun, D., Zhang, Y., Fang, H.-C., Day, A. H., \& Turan, O. (2017a). Effect of barnacle fouling on ship resistance and powering. Biofouling, 33(10), 819-834.

doi:10.1080/08927014.2017.1373279

Farkas, A., Degiuli, N., \& Martić, I. (2018). Towards the prediction of the effect of biofilm on the ship resistance using CFD. Ocean Engineering, 167, 169-186.

doi:https://doi.org/10.1016/j.oceaneng.2018.08.055

Ferziger, J. H., \& Peric, M. (2002). Computational Methods for Fluid Dynamics: Springer-Verlag Berlin Heidelberg.

Flack, K. A., \& Schultz, M. P. (2010). Review of Hydraulic Roughness Scales in the Fully Rough Regime. Journal of Fluids Engineering, 132(4), 041203-041203-041210. doi:10.1115/1.4001492

Granville, P. S. (1958). The frictional resistance and turbulent boundary layer of rough surfaces. J. Ship Res., 2(3), 52-74.

Granville, P. S. (1978). Similarity-law characterization methods for arbitrary hydrodynamic roughnesses. Retrieved from Bethesda, MD:

Kim, W. J., Van, S. H., \& Kim, D. H. (2001). Measurement of flows around modern commercial ship models. Experiments in Fluids, 31(5), 567-578. doi:10.1007/s003480100332

Larsson, L., Stern, F., \& Visonneau, M. (2013). CFD in Ship Hydrodynamics-Results of the Gothenburg 2010 Workshop. In L. Eça, E. Oñate, J. García-Espinosa, T. Kvamsdal, \& P. Bergan (Eds.), MARINE 2011, IV International Conference on Computational Methods in Marine Engineering: Selected Papers (pp. 237-259). Dordrecht: Springer Netherlands.

Lewis, E. V. (1988). Principles of Naval Architecture : Resistance, Propulsion and Vibration: 2 Jersey City: The Society of Naval Architects and Marine Engineers.

Li, C., Atlar, M., Haroutunian, M., Norman, R., \& Anderson, C. (2019). An investigation into the effects of marine biofilm on the roughness and drag characteristics of surfaces coated with different sized cuprous oxide (Cu2O) particles. Biofouling, 1-19. doi:10.1080/08927014.2018.1559305 
Menter, F. R. (1994). Two-Equation Eddy-Viscosity Turbulence Models for Engineering Applications. AIAA Journal, 32(8), 1598-1605.

Nikuradse, J. (1933). Laws of flow in rough pipes. NACA Technical Memorandum, 1292.

Owen, D., Demirel, Y. K., Oguz, E., Tezdogan, T., \& Incecik, A. (2018). Investigating the effect of biofouling on propeller characteristics using CFD. Ocean Engineering. doi:https://doi.org/10.1016/j.oceaneng.2018.01.087

Raven, H. C., Ploeg, A. van. der., Starke, A. R., \& Eça, L. (2008). Towards a CFD-based prediction of ship performance - progress in predicting full-scale resistance and scale effects. A. Transactions of the Royal Institution of Naval Architects Part A: International Journal of Maritime Engineering 150(A4)

Richardson, L. F. (1910). The approximate arithmetical solution by finite differences of physical problems involving differential equations, with an application to the stresses in a masonry dam. Transcations of the Royal Society of London. Series A, 210, 307-357.

Schultz, M. P. (2002). The Relationship Between Frictional Resistance and Roughness for Surfaces Smoothed by Sanding. Journal of Fluids Engineering, 124(2), 492-499. doi:10.1115/1.1459073

Schultz, M. P. (2004). Frictional Resistance of Antifouling Coating Systems. Journal of Fluids Engineering, 126(6), 1039-1047. doi:10.1115/1.1845552

Schultz, M. P. (2007). Effects of coating roughness and biofouling on ship resistance and powering. Biofouling, 23(5), 331-341. doi:10.1080/08927010701461974

Schultz, M. P., \& Flack, K. A. (2005). Outer layer similarity in fully rough turbulent boundary layers. Experiments in Fluids, 38(3), 328-340. doi:10.1007/s00348-004-0903-2

Schultz, M. P., \& Flack, K. A. (2007). The rough-wall turbulent boundary layer from the hydraulically smooth to the fully rough regime. Journal of Fluid Mechanics, 580, 381-405.

doi:10.1017/S0022112007005502

Schultz, M. P., Bendick, J. A., Holm, E. R., \& Hertel, W. M. (2011). Economic impact of biofouling on a naval surface ship. Biofouling, 27(1), 87-98. doi:10.1080/08927014.2010.542809

Shapiro, T. A., Schultz, M. P., and Flack, K. A., (2004). “The Effect of Surface Roughness on Hydrodynamic Drag and Turbulence," USNA Trident Scholar, Report No. USNA-1531-2.

Song, S., Dai, S., Demirel, Y. K., Atlar, M., Day, S., \& Turan, O. (2019a). Experimental and theoretical study of the effect of hull roughness on ship resistance. Journal of Ship Research (paper submitted to journal).

Song, S., Demirel, Y. K., \& Atlar, M. (2019b). An investigation into the effect of biofouling on the ship hydrodynamic characteristics using CFD. Ocean Engineering, 175, 122-137.

doi:https://doi.org/10.1016/j.oceaneng.2019.01.056

Song, S., Demirel, Y. K., \& Atlar, M. (2019c). An investigation into the effect of biofouling on fullscale propeller performance using CFD. Paper presented at the 38th International Conference on Ocean, Offshore \& Arctic Engineering, Glasgow. 
Song, S., Demirel, Y. K., \& Atlar, M. (2020). Penalty of hull and propeller fouling on ship selfpropulsion performance. Applied Ocean Research, 94, 102006.

doi:https://doi.org/10.1016/j.apor.2019.102006

Terziev, M., Tezdogan, T., Oguz, E., Gourlay, T., Demirel, Y. K., \& Incecik, A. (2018). Numerical investigation of the behaviour and performance of ships advancing through restricted shallow waters. Journal of Fluids and Structures, 76, 185-215. doi:https://doi.org/10.1016/j.jfluidstructs.2017.10.003

Tezdogan, T., \& Demirel, Y. K. (2014). An overview of marine corrosion protection with afocus on cathodic protection and coatings. Brodogradnja, 65, 49-59.

Tezdogan, T., Demirel, Y. K., Kellett, P., Khorasanchi, M., Incecik, A., \& Turan, O. (2015). Full-scale unsteady RANS CFD simulations of ship behaviour and performance in head seas due to slow steaming. Ocean Engineering, 97, 186-206. doi:https://doi.org/10.1016/j.oceaneng.2015.01.011

Townsin, R. L. (2003). The Ship Hull Fouling Penalty. Biofouling, 19(sup1), 9-15. doi:10.1080/0892701031000088535

Van, S.-H., Ahn, H., Lee, Y.-Y., Kim, C., Hwang, S., Kim, J., Kim, K.S. Park, I.-R. (2011). Resistance characteristics and form factor evaluation for geosim models of KVLCC2 and KCS. Paper presented at the The 2nd International Conference on Advanced Model Measurement Technology for the EU Maritime Industry, Newcastle upon Tyne, UK. 